\title{
Fluid and PET biomarkers for amyloid pathology in Alzheimer's Disease
}

Ann D. Cohen ${ }^{1 *}$, PhD, Susan M. Landau ${ }^{2,3^{*}}$, PhD, Beth E. Snitz ${ }^{4}, \mathrm{PhD}$, William E. Klunk ${ }^{1}, \mathrm{MD}, \mathrm{PhD}$, Kaj Blennow ${ }^{5,6}$, Henrik Zetterberg $5,6,7,8$

University of Pittsburgh School of Medicine Departments:

1- Psychiatry, 4- Neurology

2- Neurology Helen Wills Neuroscience Institute, University of California, Berkeley

3- Lawrence Berkeley National Laboratory, Molecular Biophysics and Integrated

Bioimaging Functional Imaging Department, Life Sciences Division

5- Clinical Neurochemistry Laboratory, Sahlgrenska University Hospital, Molndal, Sweden

6- Department of Psychiatry and Neurochemistry, Institute of Neuroscience and Physiology,

Sahlgrenska Academy at the University of Gothenburg

University College, London

7- Department of Molecular Neuroscience, UCL Institute of Neurology

9- UK Dementia Research Institute at UCL

* These authors contributed equally to this work 


\begin{abstract}
Alzheimer's disease (AD) is characterized by amyloid plaques and tau pathology (neurofibrillary tangles and neuropil threads). Amyloid plaques are primarily composed of aggregated and oligomeric $\beta$-amyloid $(A \beta)$ peptides ending at position $42(A \beta 42)$. The development of fluid and PET biomarkers for Alzheimer's disease (AD), has allowed for detection of $A \beta$ pathology in vivo and marks a major advancement in understanding the role of $A \beta$ in Alzheimer's disease (AD). In the recent National Institute on Aging and Alzheimer's Association (NIA-AA) Research Framework, AD is defined by the underlying pathology as measured in patients during life by biomarkers (Jack et al., 2018), while clinical symptoms are used for staging of the disease. Therefore, sensitive, specific and robust biomarkers to identify brain amyloidosis are central in $A D$ research. Here, we discuss fluid and PET biomarkers for $A \beta$ and their application.
\end{abstract}


Alzheimer's disease $(A D)$ is characterized by amyloid plaques and tau pathology (neurofibrillary tangles and neuropil threads), together with neuronal and synaptic degeneration, in cortical areas of the brain (Scheltens et al., 2016). Amyloid plaques are primarily composed of aggregated and oligomeric $\beta$-amyloid $(A \beta)$ peptides ending at position 42 (A 442$)$. In the recent National Institute on Aging and Alzheimer's Association (NIA-AA) Research Framework, $A D$ is defined by the underlying pathology as measured in patients during life by biomarkers (Jack et al., 2018), while clinical symptoms (or absence thereof) is used for staging of the disease. Following these criteria, brain amyloidosis is a key factor in AD, since it is the earliest change found in the Alzheimer's continuum, and the presence of biomarker signs of amyloidosis, with normal cognition and often, normal tau and neurodegeneration biomarkers, allows for a diagnosis of preclinical Alzheimer's pathologic change (or preclinical AD). Therefore, sensitive, specific and robust methods to identify brain amyloidosis are central in AD research, drug development and clinical management. In addition to early diagnosis, amyloid biomarkers can be used to monitor treatment effects of drugs targeting $A \beta$, and are essential in clinical and epidemiological studies exploring AD pathophysiology and factors related to both genetic and environmental risk. $A D$ research and development currently benefit from the availability of both fluid and positron emission tomography (PET) biomarkers to assess brain amyloidosis. Fluid and PET biomarkers provide overlapping, but partially independent, information that can be used to test hypotheses and make inferences about the neurophysiology underlying the initiation of amyloid deposition and disease progression.

\section{Fluid biomarkers for $A \beta$ pathology}

The best-established fluid biomarkers for cerebral $A \beta$ pathology are the 42 amino acid form of $A \beta$ (AB42) and the $A \beta 42 / 40$ ratio when measured in cerebrospinal fluid (CSF) (Ashton et al., 2018). Numerous studies have consistently shown a decrease in CSF A 342 in the dementia stage of $A D$, with meta-analysis results across 131 studies showing a mean reduction to $56 \%$ of levels found in cognitively unimpaired elderly (Olsson et al., 2016). The pathophysiological mechanism underlying the reduction of CSF $A \beta 42$ in $A D$ cases is probably that this hydrophobic $A \beta$ peptide aggregates and forms plaques in the brain, lowering the amounts being secreted to 
the CSF (Andreasen et al., 1999). The CSF also contains numerous other A $\beta$ species (especially C-terminally truncated variants), with $A \beta 40$ being most abundant (Portelius et al., 2008). Since $A \beta 40$ does not self-aggregate into plaques in the same way $A \beta 42$ does, the use of a CSF $A \beta 42 / 40$ ratio is a strategy to identify $A D$-related reductions in brain $A \beta 42$ deposition with improved diagnostic performance compared to the use of CSF A 42 by itself (Hansson et al., 2007, Janelidze et al., 2016, Wiltfang et al., 2007).

Importantly, CSF $A \beta 42$ and the $A \beta 42 / 40$ ratio are also effective for identifying brain amyloidosis in the earliest symptomatic stages of $A D$. An initial study paper reported that $\mathrm{MCl}$ patients who later progressed to AD dementia had low $A \beta 42$ at baseline (Andreasen et al., 1999). A larger study with an extended (4-7 years) clinical follow-up period also showed a very high diagnostic accuracy of CSF $A \beta 42$ to predict progression from $\mathrm{MCl}$ to $A D$ dementia, and to differentiate prodromal $A D$ cases from those having stable $\mathrm{MCl}$ and those developing other neurodegenerative dementias (Hansson et al., 2006). This finding was validated in several large multi-center studies (Mattsson et al., 2009, Shaw et al., 2009, Visser et al., 2009).

It has been difficult to establish robust blood biomarkers for $A \beta$ pathology in AD. A $\beta$ peptides can be measured in plasma but historically the correlation with $A D$ and/or cerebral $\beta$ amyloidosis has been absent or weak (statistically significant but clinically meaningless)(Olsson et al., 2016). It has been suggested that plasma $A \beta$ concentrations are potentially influenced by production in platelets and other extra-cerebral tissues and these plasma $A \beta$ measurements have been confounded by matrix effects from plasma proteins (Ashton et al., 2018). Furthermore, the vast majority of peripheral $A \beta$ studies have concentrated on plasma/serum and do not take into account peptides bound to plasma proteins and blood cells. However, this view is now starting to change. Recent mass spectrometric studies suggest that a ratio of a certain APP fragment (APP669-711) to $A \beta 42$ or $A \beta 42 / A \beta 40$ identifies $A \beta$-positive individuals with high sensitivity and specificity (Kaneko et al., 2014, Nakamura et al., 2018, Ovod et al., 2017). Nakamura and colleagues have described $91 \%$ and $87 \%$ accuracy for predicting $11 \mathrm{C}-\mathrm{PiB}$ in $\mathrm{AD} / \mathrm{MCl}$ and cognitively normal populations respectively (Nakamura et al., 2018). These results are in line with earlier data obtained using the ultrasensitive Simoa technology by which the sample can be diluted to remove confounding matrix effects in the $A \beta$ measurement 
(Janelidze et al., 2016). In this study, it was also shown that plasma $A \beta 42$ was decreased in AD compared with $\mathrm{MCl}$, subjective cognitive decline (SCD) and controls, whereas the $A \beta 42 / A \beta 40$ ratio could distinguish $\mathrm{MCl}$ from controls (Janelidze et al., 2016).

\section{PET imaging of $A \beta$ Pathology}

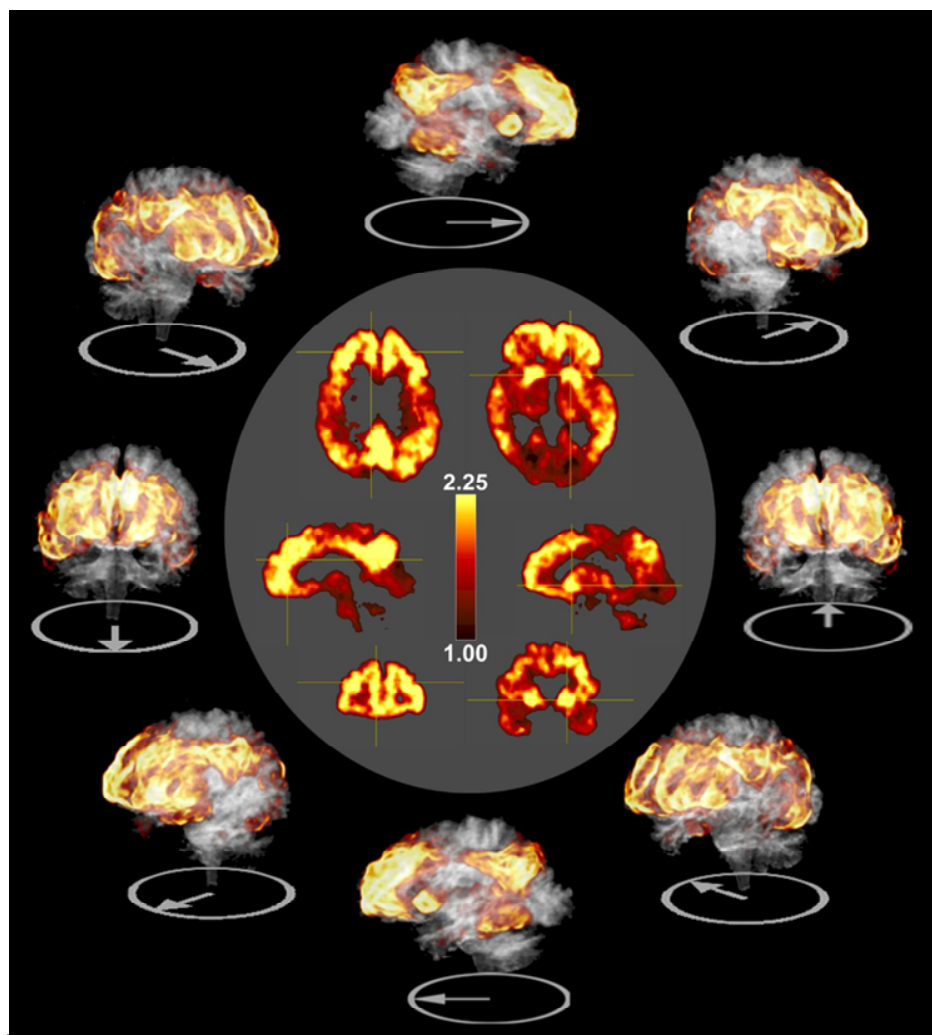

Figure 1. The typical topology of $A \beta$ deposition observed with $A \beta$ PET tracers. This scan of a single individual with mild $A D$ was performed with PiB and is expressed in standardized uptake value ratio (SUVR) units relative to cerebellar gray matter determined 50 70 minutes after injection. The central gray region of the figure shows 2-dimensional axial (top), sagittal (middle) and coronal (bottom) views at two levels (left and right). Around this in a clocklike fashion are arranged several 3-dimensional views of the same $\mathrm{PiB}$ scan overlaid on the subject's MRI scan rotated in 45 degree increments to show the prominent medial, lateral and inferior frontal, medial and lateral parietal and lateral temporal neocortex and striatum.
Topology of A $\beta$ PET Tracer Retention.

While there are many parallels

between the data produced by CSF A $\beta$

measurements and PET $A \beta$

measurements, two of the largest

differences are: 1) CSF assessments of

$A \beta$ deposition probably reflect more

proximal "state" phenomena, while

PET assessments more closely

approximate an integrated measure of $A \beta$ deposition over many years and 2 )

PET measurements reveal topological information that is not available with CSF. Thus, PET A $\beta$ measurements can give both quantitative information that can be regionally based (lending itself to definition of cutpoints) and qualitative information about the topology of $A \beta$ deposition in the brain (lending itself to visual reading) (Cohen et al., 2013).

The pattern of deposition in $A D$ and the sequence of regional development of that pattern has proven relatively consistent across individuals and across the various $A \beta$ tracers. In general, this pattern is consistent with the pattern predicted by neuropathological studies 
(Braak and Braak 1997, Thal et al., 2002). Figure 1 shows this pattern in a single individual with mild $A D$. A single individual is used rather than a group mean because it emphasizes the few asymmetries that can be seen (and would be masked in group averages such as can be seen in (Klunk et al., 2015)). The pattern of tracer retention in well-established A $\beta$ deposition is clearly much greater in gray matter areas compared to white matter areas and clearly greater in association cortices (frontal, parietal and temporal) compared to primary sensory-motor cortices. Unlike tangle pathology, the medial temporal lobe and hippocampus are not areas of highest tracer retention. Early in the application of $A \beta$ PET imaging, this distribution was recognized as mirroring the default mode network (Buckner et al., 2005).

The most notable exception to the above description is the deposition of $A \beta$ in the striatum. This is clearly seen in the scan from an individual with late-onset AD in Figure 1 but is seldom the first area where $A \beta$ deposition is visually detectable in late-onset disease. The opposite is often true with early-onset autosomal dominant AD mutations (Bateman et al., 2012, Benzinger et al., 2013, Klunk et al., 2007, Koivunen et al., 2008, Remes et al., 2008, Villemagne et al., 2009a, Yau et al., 2015) and in individuals with Down syndrome (Annus et al., 2016, Handen et al., 2012, Landt et al., 2011, Lao et al., 2016). In these cases, striatal A $\beta$ deposition is prominent early and, in some cases, can be the only detectable site of $A \beta$ deposition early in the course of the disease.

The other common atypical topology is seen with cerebral amyloid angiopathy (CAA) (Johnson et al., 2007a). In CAA, where occipital vascular $A \beta$ deposition and resultant occipital hemorrhages are common, occipital $A \beta$ tracer retention is also common, and the ratio of occipital-to-frontal retention is typically near 1.0 whereas this ratio is typically near 0.85 in AD (Johnson et al., 2007a). As with the striatum in ADAD mutations, this occipital predominance can become extreme in early-onset cases of CAA caused by mutations in the APP gene (Greenberg et al., 2008).

The sequence of events of $A \beta$ deposition in typical late onset disease is remarkable for a tight correlation between $A \beta$ load across all the cortical association areas and striatum. This was recognized very early in the evaluation of $A \beta$ tracers (Price et al., 2005 ) and has been emphasized in more recent work (Whittington et al., 2018). Analytic approaches used by 
Whittington et al. support the conclusion that " $A \beta$ accumulation starts in all brain regions simultaneously and that its spatiotemporal distribution is due to heterogeneous regional carrying capacities (regional maximum possible concentration of $A \beta$ ) for the aggregated protein rather than to longer-term spreading from seed regions." This statement may seem somewhat counter-intuitive to those used to viewing $A \beta$ PET scans across a wide range of disease severity where there is a clear pattern of early deposition in the medial frontal and medial parietal (i.e., precuneus) cortices. This apparent early deposition may seem at odds with the Whittington conclusions, but is probably more to do with the detection capabilities of the human eye and effects of brain anatomy. The brain areas that are destined to develop the highest $A \beta$ deposition will be those that are first noticed as distinct from background by the human eye. Whittington et al. (Whittington et al., 2018) report that, "the carrying capacity was highest in the anterior cingulate gyrus, precuneus, and frontal operculum cortex $(1.55,1.50$, and 1.46 SUVr units, respectively), intermediate in parts of the frontal cortex and insular cortex (1.13 and 1.19), and lowest in the thalamus and brain stem (0.48 and 0.38$)^{\prime \prime}$ - an order consistent with that commonly seen on visual reads. In addition, tracer retention on the convex surfaces of the cortex that abut CSF is muted to some degree by partial volume effects that would be less applicable to medial frontal (i.e. anterior cingulate) and medial parietal (i.e., precuneus) cortices where the two hemispheres nearly touch; being separated only by the thin falx cerebri. Even quantitative data identifies the anterior cingulate and precuneus as being most useful for distinguishing "positive" from "negative" A $\beta$ PET scans (see below for a discussion of cutoffs) although the other cortical association areas and striatum fall close behind, and all are well above other brain areas (Cohen et al., 2013).

The consistency in the late-stage topology and the sequential development of the topology of $A \beta$ deposition determined by $A \beta$ PET has led to a staging scheme reminiscent of those used in neuropathology (Braak and Braak 1997, Thal et al., 2002). Although still controversial, Grothe et al. (Grothe et al., 2017a) have proposed a four-stage system based on ADNI [F-18]florbetapir data. This staging system suggests a progression pattern from: 1) temporobasal and frontomedial areas; 2 ) the remaining associative neocortex; 3) primary sensory-motor cortex and the medial temporal lobe; and 4) the striatum. Controversy remains 
about: 1) the earliest appearance of $A \beta$ deposition in the temporobasal area and 2) primary sensory-motor cortex preceding striatum. The quantitative methods used in the Grothe et al. study to define $A \beta$-positivity may be the explanation for differences in this study and the general description provided above.

In summary, it appears that $A \beta$ deposition behaves more like a rising tide in all brain areas simultaneously, limited by the ultimate capacity of a given brain area to generate and contain $A \beta$ deposition. This contrasts with the sequential regional spread of tau pathology from medial temporal lobes throughout the neocortex (Braak and Braak 1991). When viewed with the human eye, or many quantitative approaches, $A \beta$ deposition in certain brain areas becomes detectable before other brain areas. The late-stage pattern is not homogeneous across the brain and clear differences exist in the regional magnitude of $A \beta$ deposition reflecting what has been termed the "carrying capacity" of the various brain regions (Whittington et al., 2018).

Biphasic Pattern of Longitudinal Change in A $\beta$ Deposition. The very well-known hypothetical model of dynamic biomarkers of Jack et al. (Jack et al., 2013) describes a sigmoid course of $A \beta$ deposition over time. The implication of this model is that "change in $A \beta$ deposition" over "change in time" (i.e., $d A \beta / d t$ : the derivative of the sigmoid curve) will approximate a biphasic, bell-shaped curve. That is, although the rate of $A \beta$ deposition is expected to accelerate early in the disease course, this rate should slow - and perhaps stop later in the disease. There are now three empirical studies that support this model using crosssectional data (Jack et al., 2013, Villain et al., 2012, Vlassenko et al., 2011). In addition, there are longitudinal studies of persons with autosomal dominant AD mutations followed for up to 10 years that support this model on a single-subject basis (Yau et al., 2015). The pathophysiological basic of this non-linear, biphasic pattern is not entirely clear. It is consistent, however, with the concept of "carrying capacity" (discussed above) proposed for modeling $A \beta$ deposition (Whittington et al., 2018) that defines the maximum possible concentration of $A \beta$ in a brain region. What's more, the maximum carrying capacity varies across brain regions within an individual and the maximum carrying capacity varies across individuals within a given region. Possible explanations include: 1 ) decreased production of $A \beta$ as neurons die; 2) clearance of previously deposited $A \beta$ as the brain atrophies; and 3) the apparent plateau of $A \beta$ deposition 
could be an artifact of changes in the structure of $A \beta$ over time that leave the binding sites for

the $A \beta$ tracers less accessible. The first explanation is supported by a report of decreased in $A \beta$ deposition with neurodegeneration in the amygdala of individuals with Down syndrome in the late stages of AD (Wegiel et al., 1999).

Another important finding in all of these reports was that $A \beta$ accumulation could be detected over time in individuals who were cutpoint-defined "A $\beta$-negative" at baseline (Jack et al., 2013, Villain et al., 2012, Vlassenko et al., 2011). This clearly points out the imperfect nature of all cutpoints given the inevitable tradeoff between sensitivity and specificity in any dichotomous measure. It also points out the added value of a longitudinal trajectory of an $A \beta$ PET measure compared to any baseline measure of pathology. Once individuals are adjudicated $A \beta$-positive, they very rarely revert to $A \beta$-negative status. However, in any group of $A \beta$-negative individuals adjudicated by a cutpoint, there will exist sub-threshold $A \beta$-positive individuals who will convert to $A \beta$-positive status over the next few years. This has implications for correlations of cognition, clinical progression and other measures with dichotomous measures of $A \beta$ deposition and also has implications for clinical trials that focus on "A $\beta$ negative" individuals. A recent study on familial AD found that rates of $A \beta$ deposition, according to either cortical PiB uptake or CSF A 42 , accelerated in carriers around 25 years before symptom onset (McDade et al., 2018), in keeping with cross-sectional data from in people at risk of sporadic AD (Jansen et al., 2015a).

\section{CSF and PET associations}

CSF and PET measurements of $A \beta$ are inversely related to one another such that individuals with greater $A \beta$ burden show elevated cortical $A \beta$ PET while CSF $A \beta_{1-42}$ is reduced (Ashton et al., 2018). As discussed above, these measures capture different features of $A \beta$ pathology. $A \beta$ PET retention is a reflection of the net accumulation of fibrillar $A \beta$ burden, while lowered CSF is an index of the current status of $A \beta$ production versus clearance, suggesting that CSF is sensitive to oligomeric forms of abnormal $A \beta$ pathology that can be detected earlier in the course of disease progression and are more toxic and more closely linked to cognitive symptoms (McLean et al., 1999). These differences have been useful for the generation of 
hypotheses about how CSF and PET measurements contribute different and complementary information about disease progression and relationships with other biomarkers (Jansen et al., 2015b).

Despite differences in the biology underlying PET and CSF measurements of $A \beta$, agreement in dichotomous (positive/negative) A $\beta$ status measured by PET and CSF is

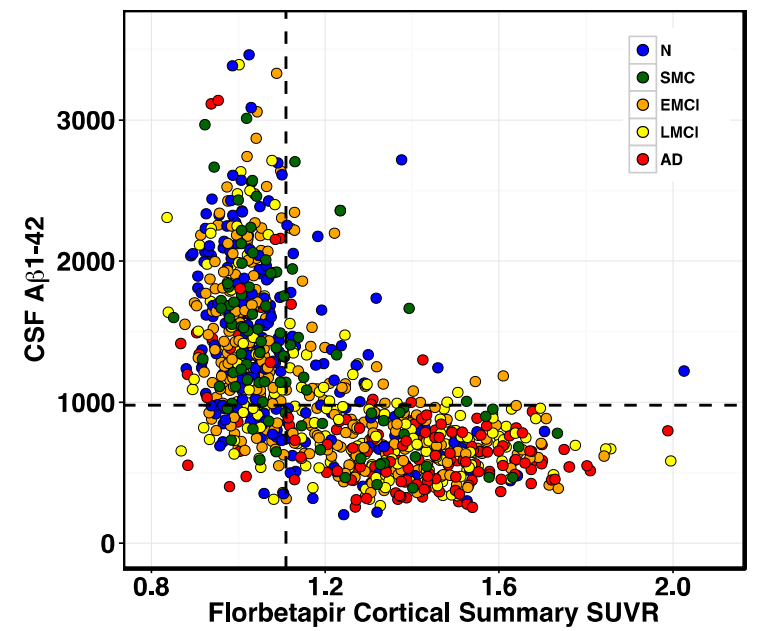

Figure 2. Cortical florbetapir PET SUVRs (relative to whole cerebellum) and CSF A $\beta_{1-42}$ (Roche Elecsys ${ }^{\circledR}$ automated immunoassay platform; see adni.loni.usc.edu/methods) for 888 Alzheimer's Disease Neuroimaging Initiative participants (192 cognitively normal, 93 subjective memory complaint, 273 early $\mathrm{MCl}, 119$ late $\mathrm{MCl}, 152 \mathrm{AD}$ ) who had a lumbar puncture and florbetapir-PET scan within 1 year. Thresholds (1.11 for florbetapir and $980 \mathrm{pg} / \mathrm{mL}$ for CSF $A \beta_{1-42}$ ) are described in in the ADNI Study Data methods documents (ida.loni.usc.edu). nonetheless relatively high, with concordance between the two modalities ranging from about 73\%-87\% (Fagan et al., 2009, Jansen et al., 2015b, Landau et al., 2013b, Schindler et al., 2018). In a recent examination of $888 \mathrm{ADNI}$ participants with contemporaneous PET and CSF measurements, $83 \%$ were concordant on both measures $(36 \%$ positive, $47 \%$ negative), and $17 \%$ were discordant (10\% CSF+ and PET-, 7\% PET+ and CSF-) (see Figure 2).

PET-CSF concordance is further improved with the use of recently-developed automated CSF assays as opposed to ELISA-based immunoassays (Bittner et al., 2016, Schindler et al., 2018) and the use of the CSF $A \beta_{1-42} / A \beta_{1-40}$

ratio in order to account for individual differences in total A $\beta$ production (Leuzy et al., 2016, Lewczuk et al., 2017, Pannee et al., 2016, Schindler et al., 2018), although use of the ratios did not increase concordance in all studies (Zwan et al., 2014, Zwan et al., 2016). Overall, however, the reasonably high CSF-PET concordance has provided justification for merging PET and CSF measures of $A \beta$ status in order to create larger and/or more heterogeneous study samples (Donohue et al., 2017, Ewers et al., 2012, Jansen et al., 2015a). Indeed, the updated NIA-AA Research Framework advocates for interchangeable use of PET-CSF in the ATN system for classifying subjects based on normal or abnormal A $\beta$ status (" $A$ ") as measured by either CSF or 
PET, normal or abnormal CSF or PET tau ("T"), and presence or absence of neurodegenerative changes (“N") (Jack et al., 2018).

Understanding the biological and methodological factors that account for CSF-PET A $\beta$ discordance, however, is an important focus of many comparison studies. Because CSF A $\beta_{1-42}$ measures appear to reflect soluble forms of $A \beta$ that precede fibrillary $A \beta$ deposition (Blennow et al., 2015), CSF-PET comparison studies have provided insight into the earliest stages of pathological change. Among individuals who are discordant on PET and CSF, a larger proportion of "CSF+ only" compared with "PET+ only" discordant individuals has been frequently reported (Fagan et al., 2009, Fagan et al., 2011, Leuzy et al., 2016, Palmqvist et al., 2016). Furthermore, $A \beta$ positivity among APOE4-positive individuals has also been observed at earlier ages with CSF measurements compared to PiB-PET (Morris et al., 2010). These findings have provided the foundation for the hypothesis that CSF $A \beta_{1-42}$ becomes abnormal prior to A $\beta$ PET (Jack et al., 2013). This temporal offset in PET and CSF changes may play an important role in how these measures are implemented in a clinical setting and in selection of participants for clinical trials of $A \beta$-targeting drugs, particularly because of the increasing emphasis on $A \beta$ reduction during the earliest possible stage.

CSF and PET measures are frequently assessed as dichotomous variables (e.g. concordance in +/- status) as opposed to continuous variables (e.g. correlation) for simplicity because of the bimodal nature of $A \beta$ that facilitates division of individuals into positive and negative groups. However, while CSF and PET A $\beta$ measurements are both bimodal, and are inversely related, their distributions differ. PET measurements have little variability in the normal range (low values) and greater variability in the abnormal range (high values)(Klunk et al., 2015), while CSF $A \beta_{1-42}$ measurements show the opposite pattern: greater variability in the normal range (high values) and lower variability in the abnormal range (low values)(Zetterberg et al., 2007) (Figure 2). While elevated PET has been associated with greater pathology at autopsy (Clark et al., 2011, Sabri et al., 2015) and more abnormal CSF measurements are linked to greater pathology at autopsy (Strozyk et al., 2003), it is unclear whether variability within the positive or negative ranges for either measure has pathological or clinical relevance. Continuous PET and CSF values at the low and high ends of their dynamic range appear to be unrelated 
(Toledo et al., 2015), although the available data that directly addresses this is limited. This indicates that among individuals who are $A \beta+$ on both CSF and PET, for example, continuous PET and CSF measurements within the $A \beta+$ range are not related, even as dichotomous PET and CSF measures agree. This absence of a continuous PET-CSF association among individuals who are $A \beta+$ (or among individuals who are $A \beta-$ ) calls into question whether variability within the negative range or within the positive range is clinically meaningful. For example, it is unclear how to interpret the clinical and biological significance of a highly elevated A $\beta$ PET with only borderline positive CSF $A \beta_{1-42}$, occurring in $15-20 \%$ of subjects. This question further reinforces the observation that PET and CSF assess fundamentally different features of A $\beta$ pathology.

A number of methodological issues influence the degree of CSF-PET concordance. First, differences in PET ligands and CSF analysis platforms likely influence the dynamic range of measurements and perhaps their sensitivity within the positive or negative ranges. Second, the sensitivity and specificity of the selected threshold for each measure determines who is categorized as positive or negative. The gold standard for determining $A \beta$ positivity is autopsybased validation of PET and/or CSF measurements carried out close to the end of life, but these studies are relatively rare (Clark et al., 2011, Sabri et al., 2015, Shaw et al., 2009). A $\beta$ positive/negative status, determined by either pathology or visual reads on PET data, is often used to validate a CSF positivity threshold (Zwan et al., 2016), introducing the possibility of circularity if the thresholds are used to determine PET/CSF concordance. Finally, the makeup of the sample affects whether the entire dynamic range of $A \beta$ is sampled as opposed to just the negative or positive range. CSF-PET concordance is frequently lower among cognitively normal subjects, with a larger proportion of "CSF+ only" than "PET+ only"(Fagan et al., 2009, Jansen et al., 2015b, Leuzy et al., 2016, Palmqvist et al., 2016), supporting the idea that CSF becomes abnormal prior to PET. However, "PET+ only" individuals have also been observed across samples that include both cognitively normal and impaired subjects(Forsberg et al., 2010, Koivunen et al., 2008, Landau et al., 2013b, Leuzy et al., 2015, Mattsson et al., 2014, Zwan et al., 2016), suggesting that PET abnormality may in some cases precede CSF abnormality, and/or that differing samples and methodologies likely influence the proportions of CSF+ and/or PET+ individuals (Leuzy et al., 2016). Cases of abnormal CSF A $\beta$ in the absence of elevated A $\beta$ PET 
have also been reported in unusual clinical cases such as early onset AD related to the Arctic APP mutation(Scholl et al., 2012), suggesting that varying sensitivities to different forms of $A \beta$ (e.g. soluble, fibrillary) likely contribute to CSF-PET concordance.

Overall, reasonably high concordance of CSF and PET measures of A $\beta$ pathology in symptomatic disease stages supports their interchangeable use in diagnostic criteria to determine if an individual is $A \beta$-positive or $A \beta$-negative. However, inconsistencies across studies point to the need for longitudinal CSF and PET measured in the same subjects using consistent methodology in order to understand how their longitudinal trajectories related to each other. While a few studies have reported longitudinal PET, CSF, and/or clinical followup in the same individuals, data has been limited or incomplete (e.g. longitudinal PET but not CSF). Palmqvist and colleagues showed that the rate of florbetapir-PET accumulation was comparable in CSF+ only individuals and those who were abnormal on both, supporting the idea that the CSF abnormality preceded the $A \beta$ accumulation that was subsequently observed in these individuals(Palmqvist et al., 2016). Large cohorts that are measuring both CSF and PET longitudinally will be critical for understanding the shapes of their trajectories in concert as well as their clinical significance at different stages of disease.

\section{Detection of the earliest signs of amyloid deposition}

Since the initial PiB-PET studies, the focus of many research studies has shifted away from the robust signal seen in symptomatic $A D$ and towards detection of the earliest signs of fibrillar $A \beta$ pathology in cognitively normal individuals. This shift towards initial detection has generated a need for reliable methods that can distinguish brains free of fibrillar $A \beta$ from brains that have early-stage fibrillar $A \beta$ deposition. It is important that such methods can be standardized and applied across many centers.

Defining amyloid positivity. As discussed above, $A \beta$ tracer retention is a continuous measure and need not necessarily be dichotomized into positive and negative. This approach may be preferred for some applications, however, in other applications it is necessary to dichotomize subjects into $A \beta(+)$ and $A \beta(-)$. This may be most important in the cognitively normal subjects when attempting to disentangle the effects of normal aging from the effects of 
preclinical AD (Sperling et al., 2011). Further, with the recent proposal of the NIA-AA preclinical $A D$ definition and staging, cutoffs for amyloid-positivity will be crucial for appropriate defining disease status (Dubois et al., 2016).

A variety of ad hoc objective approaches have been presented to define an amyloidpositive cutoff using amyloid imaging. These methods include using one or two standard deviations above the mean of the control data (Edison et al., 2008, Kemppainen et al., 2007, Klunk et al., 2004a, Okello et al., 2009); inspection of quantitative PET data for natural breakpoints in the distribution of tracer retention in combinations of young controls, elderly controls and/or AD patients,(Edison et al., 2008, Hedden et al., 2009, Jack et al., 2008, Maetzler et al., 2009, Mintun et al., 2006, Mormino et al., 2011, Morris et al., 2010, Roe et al., 2008, Rowe et al., 2007); the low end of the range of tracer retention in clinically (Sperling et al., 2009) or pathologically defined AD patients (Fleisher et al., 2011); receiver operating characteristic (ROC) analyses of PET data from control and AD subjects (Devanand et al., 2010, Mormino et al., 2009, Ng et al., 2007, Pike et al., 2007); visual reads (Clark et al., 2012, Engler et al., 2007, Gomperts et al., 2008, Johnson et al., 2007b, Joshi et al., 2012, Ng et al., 2007, Rabinovici et al., 2007, Sabri et al., 2015, Suotunen et al., 2010); and cluster analysis methods using both $\mathrm{PiB}(+)$ and $\mathrm{PiB}(-)$ elderly control subjects (Bourgeat et al., 2010, Cohen et al., 2013). Each approach has advantages and shortcomings. Most of these approaches involve subjective choices such as the number of standard deviations above the control mean, the exact location of the natural breakpoints and the interpretation of the visual read. Others, like ROC analysis or using the low end of the $A D$ range, rely on the composition of the $A D$ group, which can vary widely depending on the nature of the particular control or AD population utilized. Methods that rely on analysis of the entire control group can result in cutoffs that are unduly affected by the amyloid-positive high outliers in the control group (e.g., control mean + standard deviations). Additionally, it has also been suggested that, in general, applied thresholds for PiBpositivity are overly stringent and it has been shown that lower thresholds resulted in higher sensitivity without compromising specificity when compared to post-mortem A $\beta$ load (Villeneuve et al., 2015); see $\boldsymbol{A} \beta$ PET and neuropathological associations below. However, it has also been shown that cutoffs for establishing positive and negative $A \beta$ status can be 
accurately transformed between radioligands and processing methods, with conversion of PiB thresholds for florbetapir largely agreeing with independently established florbetapir thresholds (Landau et al., 2013a).

Subthreshold change in amyloid. The emergence of longitudinal amyloid imaging data has highlighted the importance of early, sub-threshold changes in $A \beta$ deposition and their clinical relevance. Indeed, when examining post-mortem correlations of slightly elevated, premortem PiB values many of such individuals show moderate CERAD ratings at autopsy, suggesting that these lower values may be of clinical importance (Sojkova et al., 2011). Interestingly, it has been shown that in individuals with PiB values that were rated as "ambiguous" were primarily in brain regions known to accumulate amyloid, suggesting that longitudinal follow-up is needed in such cases to elucidate the meaning of these small elevations in tracer retention (Mormino et al., 2012). More recently, it has been shown that among PiB-negative $\mathrm{MCl}$ patients, those with slightly elevated $\mathrm{PiB}$ in posterior cingulate cortex are more likely to become PiB-positive and convert to AD at followup (Ye et al., 2018).

Additionally, it has been shown that older APOE e4 carriers have greater longitudinal increases in $A \beta$ than younger, non-carriers, but only in the $A \beta$-negative group, suggesting that in certain groups at higher risk for $A D$, small sub-threshold increases in $A \beta$ are present (Lim et al., 2017). Such sub-threshold levels of $A \beta$ and the rate of amyloid accumulation predicted early tau deposition in brain regions associated with $A D$. both the rate of amyloid accumulation and the baseline levels of $A \beta$ predicted early tau deposition in cortical Braak regions associated with $A D$ (Leal et al., 2018). In another recent analysis of participants with 10 years of imaging follow-up, it was demonstrated that using a conventional threshold for A $\beta$-positivity, subtle signs of cognitive dysfunction can be observed more than 10 years prior to $A \beta$-positivity (Insel et al., 2017). Taken together, these data suggest that changes in $A \beta$ that occur below the traditional $A \beta$ thresholds are likely relevant and important to the pathogenic process of $A D$.

\section{In Vivo versus neuropathological $\mathrm{A} \beta$ measurements}

CSF $\boldsymbol{A} \beta$ and neuropathological associations. While amyloid PET gives an estimate of brain amyloidosis, evaluation of plaque and tangle counts at autopsy is commonly regarded as 
the "gold standard" for AD diagnosis. The diagnostic accuracy of CSF A $\beta 42$ against neuropathological diagnosis has been evaluated in five studies, showing a mean sensitivity of CSF A $\beta 42$ of around $90 \%$ and a ROC value of 0.90 (Shaw et al., ), and in some studies such as the ADNI study, the sensitivity for CSF $A \beta 42$ was $96 \%$ (Shaw et al., 2009). The specificity in these studies were somewhat lower, probably due to the fact that the control groups were based on clinical evaluations and rating scales, and not amyloid pathology, making inclusion of cognitively unimpaired elderly with clinically silent brain amyloidosis possible, thereby reducing specificity estimations. Another drawback may be the latency between CSF samples taken during life and later post-mortem evaluations of pathology. For these reasons, clinical studies evaluating the concordance between CSF A $\beta 42$ and amyloid PET have been very important and are reviewed in the section below.

$\boldsymbol{A} \beta$ PET and neuropathological associations. A $\beta$ PET is somewhat unique as a molecular imaging technology because - as a requirement for regulatory agency approval as a clinical tool - it has been validated by postmortem confirmation of its ability to detect its target pathology (Clark et al., 2012, Curtis et al., 2015, Sabri et al., 2015). Two issues should be fully understood before evaluating any in vivo-postmortem correlation of $A \beta$ PET. The first is the fact that no in vivo measure of pathology will be as sensitive as modern postmortem histological and biochemical measures of pathology. Second, and most important, none of the neuropathological criteria for the diagnosis of $A D$ were designed to be a quantitative measurement of the fibrillar $A \beta$ pathology which is the substrate of $A \beta$ PET tracer retention. These neuropathological criteria were designed to obtain an accurate clinical diagnosis and/or staging in the most efficient manner and they do a very good job in this regard (Braak and Braak 1991, Hyman and Gomez-Isla 1997, Hyman et al., 2012, Mirra et al., 1991). A $\beta$ PET is a quantitative measure of regional or whole brain fibrillar $A \beta$ deposition. The requirement for fibrillar $A \beta$ has been demonstrated by formic acid ablation of the binding of $A \beta$ tissue stains which are chemically related to A $\beta$ PET tracers (e.g., (Styren et al., 2000)). If one were to design a "gold standard" against which to measure the accuracy of A $\beta$ PET, it would likely rely on a truly quantitative biochemical method such as extraction of whole brain or region-matched insoluble $A \beta$ followed by quantitative analysis by ELISA or mass spectrometry. This is a very 
different standard of truth than those offered by the common neuropathological approaches. By necessity for clinical application, these approaches use only a very small fraction of total brain volume when counting pathology and tend to score pathology based on the most heavily affected regions rather than by averaging across regions. In addition, the most commonly applied standard of truth for the Phase 3 studies for approval of the three clinically used $A \beta$ tracers (i.e., CERAD; (Mirra et al., 1991)) is based upon detection of a combination of tau and $A \beta$ pathology in neuritic plaques. The take home point is that neither A $\beta$ PET nor neuropathological criteria for $A D$ were designed to validate the other. The main question answered in the Phase 3 studies is "do they reach the same conclusion regarding clinical diagnosis?" In the three studies performed to-date the answer is yes with sensitivities in the range of $88-98 \%$ and specificities in the range of $88-100 \%$ (Clark et al., 2012, Curtis et al., 2015, Sabri et al., 2015).

Aside from the above validation of the clinical diagnostic use of A $\beta$ PET in the Phase 3 studies that were completed between 2012 and 2015 for the three A $\beta$ PET tracers now approved for clinical use, single detailed case reports (Bacskai et al., 2007, Cairns et al., 2009, Ikonomovic et al., 2012, Ikonomovic et al., 2008) and small autopsy or biopsy series (Burack et al., 2010, Leinonen et al., 2008, Sojkova et al., 2011, Villemagne et al., 2009b) showed a clear correspondence between in vivo retention of $\mathrm{PiB}$ and $\mathrm{A} \beta$ pathology. In these more basic studies, it is important to choose the method of postmortem analysis that best reflects the in vivo target - fibrillar $A \beta$. As mentioned above, the optimal postmortem correlate for in vivo amyloid imaging would be a specific measure of total fibrillar $A \beta$ pathology by the use of sensitive and specific anti-A $\beta$ antibodies or mass spectrometry. The literature contains reports of 24 cases that had been studied with PiB PET prior to autopsy $(n=14)$ or after biopsy $(n=10)$ that have been previously reviewed (Klunk 2011). These studies meet these methodological goals to varying degrees but also provide important insights about the sensitivity and specificity of in vivo PiB PET amyloid imaging for detecting the presence of postmortem $A \beta$ pathology (Bacskai et al., 2007, Burack et al., 2010, Cairns et al., 2009, Ikonomovic et al., 2008, Leinonen et al., 2008, Sojkova et al., 2011, Villemagne et al., 2009b). First, in the 12 cases (out of 24 total autopsy or biopsy cases) with positive PiB PET scans in vivo, postmortem analyses confirmed 
the presence of significant $A \beta$ deposition in all of them. Thus, the specificity of PiB PET in this small sample was $100 \%$. However, PiB PET was positive in only 12 of the 15 cases that showed amyloid deposition by immunohistochemical analysis; yielding a sensitivity of $75 \%$. This is not surprising, given the discussion above that the postmortem measures are expected to be more sensitive than PET measures.

Cairns et al. (Cairns et al., 2009) have reported a single case with a negative PiB scan in the presence of biochemically and immunohistologically detectable $A \beta$ at levels expected to be detectable in vivo. In a biopsy study, Leinonen et al. reported "Case \#6" with high numbers of plaques by immunohistochemistry (although sparse neuritic plaques) but a negative PiB scan (Leinonen et al., 2008). These may represent an example of non-fibrillar amyloid deposition (i.e., a type of diffuse plaque) or other alterations in the tertiary structure of $A \beta$, as has been reported in transgenic mice (Klunk et al., 2005a, Klunk et al., 2005b, Toyama et al., 2005). Thus, as expected, the sensitivity of amyloid imaging for all forms of $A \beta$ deposits will be somewhat less than $100 \%$. However, it should be noted that none of the PiB-negative cases with postmortem $A \beta$ deposits met criteria for definite $A D$ dementia, so the sensitivity of PiB for $A \beta$ deposition in pathologically proven definite AD dementia is likely to be closer to $100 \%$ than its sensitivity for any form of $A \beta$ deposition. A similar finding has recently been published for the F18 agent, florbetapir (Clark et al., 2011).

Although the norm is clearly sensitive and specific detection of fibrillar $A \beta$ deposits both in vivo and especially ex vivo by $A \beta$ tracers, one case has proven to be an interesting exception that remains to be fully explained. Rosen et al. (Rosen et al., 2010) described a case of endstage Alzheimer's disease with extensive $A \beta$ deposition but little high-affinity binding of [H-3] Pittsburgh Compound-B. This case met histopathological criteria for AD but contained more vascular amyloid, higher levels of insoluble $A \beta 40$ and $A \beta 42$, and a higher ratio of $A \beta 40: A \beta 42$ than more typical AD cases.

\section{Standardization of amyloid biomarkers}

Standardization of CSF A $\beta$ measures. While implementation of strict quality control (QC) procedures in a clinical laboratory serves as the basis for correct measurements within 
analytical runs and over time (Palmqvist et al., 2014), differences in absolute levels between assay formats and laboratories precludes the global use of a single cutoff value for CSF A 342 . Initiatives such as the Alzheimer's Association QC program for CSF biomarkers (Mattsson et al., 2011) may guide individual laboratories and identify longitudinal assay variability, but international standardization efforts to develop a mass spectrometry-based Reference Measurement Procedure (RMP) and Certified Reference Materials (CRM) for CSF A 442 are essential to reach the highest level of standardization in Clinical Chemistry, for review see (Kuhlmann et al., 2017).

Collaborative efforts by the International Federation of Clinical Chemistry and Laboratory Medicine Working Group for CSF proteins (IFCC WG-CSF), http://www.ifcc.org/ifccscientific-division/sd-working-groups/csf-proteins-wg-csf/, and the Alzheimer's Association Global Biomarker Standardization Consortium (GBSC) have led to reference methods for $A \beta 42$ (Korecka et al., 2014, Leinenbach et al., 2014). These methods have been formally certified by the Joint Committee for Traceability in Laboratory Medicine (JCTLM database accession numbers C11RMP9 and C12RMP1), have been validated against amyloid PET, and a reference

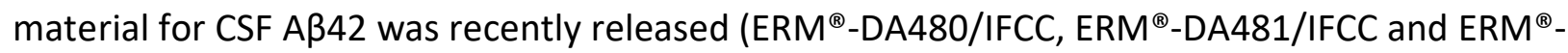
DA482/IFCC)(Kuhlmann et al., 2017).

Importantly, fully automated routine clinical chemistry assays for CSF AB42 and A 40 are now available for clinical chemistry laboratories and for use in clinical routine diagnostics. The first publication on such assays presented the full validation and analytical performance of the Cobas assay (Bittner et al., 2016). This assay shows superior performance compared with standard ELISA methods, and minimal batch-to-batch variability, and real-life evaluations of the assay in the Alzheimer's Association QC program show between laboratory coefficients of variations (CVs) of a few percent as compared with $15-20 \%$ for the ELISA methods. Other fully automated assays for CSF $A \beta 42$ and $A \beta 40$, based on the Lumipulse and RA10 instruments also show very high analytical performance and are commercially available.

The Centiloid scale. As discussed above, the CSF biomarker community has recognized the importance of standardizing the measurement of CSF A $\beta$. The measurement of $A \beta$ deposition by PET also faces standardization issues which are due mainly to the use of different 
tracers and different analysis procedures across labs. To address this problem, a working group was formed to standardize quantitative $A \beta$ PET imaging outcome measures by scaling the outcome of each particular analysis method or tracer to a 0 to 100 scale, anchored by young controls (<45 years) and typical AD patients (Klunk et al., 2015). The units of this scale are referred to as "Centiloids." This process requires an initial scaling of any non-standard method to a standard method which includes several key features: 1) the A $\beta$ PET tracer is PiB and the acquisition period is 50-70 min after injection; 2) a standard large cortical target volume-ofinterest is used; and 3) a standard reference region using whole cerebellum (gray and white matter) is employed. Any non-standard method can be scaled to this standard method by gathering data from the same subjects using both methods and then doing a linear transformation into Centiloid units as previously described in detail (Klunk et al., 2015). All commonly used F-18-labelled A $\beta$ PET tracers have been scaled to PiB including [F-18]NAV-4694 (Rowe et al., 2016), [F-18]florbetaben (Rowe et al., 2017), [F-18]florbetapir (Navitsky et al., 2018) and [F-18]flutemetamol (Battle et al., 2016). These scaled F-18 tracers can then be used to scale alternative analysis methods using these tracers to Centiloids using the necessary data for any given tracer that is publicly available on the Global Alzheimer's Association Interactive Network (GAAIN; http://www.gaain.org/centiloid-project). Although very early in the process of application, Centiloid scaling has been found helpful in several studies (Jack et al., 2017a, Jack et al., 2017b, Su et al., 2018, Tudorascu et al., 2018, Yun et al., 2017), including a study comparing data from PiB PET and CSF measures of $A \beta$ (Leuzy et al., 2016), and will be included in ADNI analyses (Weiner et al., 2017). While this standardization method shows promise in the early applications, further work is needed to determine whether scanner effects are important, and more time is needed to determine whether there will be wide adoption of this process.

\section{Prediction of $A \beta$ deposition risk}

Age Dependence of $A B$ deposition. It is well known that age is a significant risk factor for both clinical $A D$ and the presence of AD pathology (Nelson et al., 2011). Studies have demonstrated that the number of $A \beta$-positive, cognitively normal individuals increases with age from around $6 \%$ at around 60 years to $30 \%$ or greater in individuals $>80$ years (Fleisher et al., 
2011). Indeed, it was demonstrated that in 190 non-demented subjects, aged greater than 82 , a high proportion of the cognitively normal subjects (51\%) and $\mathrm{MCl}$ subjects (68\%) were PiBpositive (Mathis et al., 2013). It has also been shown in a large, cross-sectional study that the estimated age at which $10 \%$ of non-demented APOEe4 carriers were PiB-positive was 57 years compared with 64 years for noncarriers. Further, the authors demonstrated that after age 70 the median PiB-PET value was greater in carriers compared to noncarriers (Jack et al., 2015). In a similar study, it was shown using the A/T/N (Amyloid/ Tau/ Neurodegeneration) classification, that from the age of 50 onward amyloid positivity increases and that after the age of 75 , the $A+/ T+/ N+$ group is the most prevalent (Jack et al., 2017a). In a recent meta-analysis, the prevalence of amyloid pathology increased from age 50 to 90 years from $10 \%(95 \% \mathrm{Cl}, 8 \%-13 \%)$ to $44 \%$ (95\% Cl, $37 \%-51 \%)$ among participants with normal cognition; from $12 \%$ to $43 \%$ among patients with subjective memory complaints; and from $27 \%$ to $71 \%$ among patients with $\mathrm{MCl}$ (Jansen et al., 2015a). In symptomatic AD, an inverse age dependence has been demonstrated with age decreasing prevalence of amyloid-positivity, in the same meta-analysis it was shown that the prevalence of amyloid positivity decreased from age 50 to 90 years in APOE $\varepsilon 4$ noncarriers from $86 \%$ at 50 years to $68 \%$ at 90 years (Ossenkoppele et al., 2015). It has also been shown the age of onset seems to impact the amount of $A \beta$ observed, in a small study exploring differences between early and late onset $A D$, significantly higher PiB retention was observed in the early onset group, suggesting that perhaps those with late onset $A D$ are more likely to have concomitant diseases, such as vascular disease, contributing to cognitive decline (Youn et al., 2017). Interestingly, no clear age-dependent effects have been reported for CSF Aß42 in cognitively normal individuals (Sjogren et al., 2001).

Diagnosis dependence: normal cognition, $M C l$ and $A D$. A $\beta$-imaging positivity is strongly associated with cognitive status along the AD-spectrum. Single investigations since the first human studies with PiB-PET in 2004 have consistently shown highest proportions of A positivity in $A D$, lowest in groups with normal cognition (NC), and intermediate in mild cognitive impairment (MCl) (Jack et al., 2008, Johnson et al., 2013, Rowe et al., 2010, Vandenberghe et al., 2010). Two recent meta-analyses from the A $\beta$ PET Study Group contributed comprehensive syntheses of $A \beta$-positivity prevalence in dementia syndromes (Ossenkoppele et al., 2015) and in 
people without dementia (Jansen et al., 2015a). In AD dementia, integrating data across 1359 patients, mean prevalence was $88 \%$. Notably, prevalence estimates of $A \beta$-positivity in $A D$ dementia decreased with age from $93 \%$ at age 50 , to $79 \%$ at age 90 . This inverse age effect was driven by APOE e4 status: among e4 carriers, prevalence remained at least $90 \%$ regardless of age, whereas prevalence in noncarriers declined with increased age to $68 \%$ by age 90 . Lower prevalence among older APOE e4 noncarriers may reflect non-A $\beta$ pathologies (e.g., vascular, tau, alpha-synuclein and TDP-43) combined with aging-associated diminished threshold for cognitive impairment (i.e., diminished resilience). Among non-AD dementias, mean prevalence ranged from $51 \%$ in dementia with Lewy bodies (DLB), to $30 \%$ in vascular dementia, to $12 \%$ in frontotemporal dementia. Prevalence increased with age in most non-AD dementias, as well as with APOE e4 carriership. (Ossenkoppele et al., 2015)

The Jansen et al (2015a) meta-analysis of people without dementia included A $\beta$ positivity by both PET and CSF evaluation. In NC individuals, estimates of prevalence ranged from $10 \%$ to $44 \%$, as age increases from 50 to 90 years, respectively. The age-associated increase was $27 \%$ to $71 \%$ among people with $\mathrm{MCl}$, about twice as common, on average, than in NC. Notably, prevalence estimates for people with subjective cognitive impairment (SCI) were not different from NC (ranging from $12 \%$ to $43 \%$ as age increases), suggesting this diagnostic category may be too heterogeneous (or too early) for association with reliably detectable increased $A \beta$ pathology.

A population-based study published subsequent to the 2015 meta-analyses (Roberts et al., 2018) indicates there is variability by study setting. In the Mayo Clinic Study of Aging, nondemented participants in Olmstead County, MN, were selected for study based on a random sampling scheme. Prevalence estimates were generally lower than reported in clinic- or volunteer-based samples, and the expected effect of cognitive status was not observed: $18 \%$ of $\mathrm{NC}$ participants across age strata were $\mathrm{A} \beta$-positive, compared to $4 \%$ of those with $\mathrm{MCl}$. Prevalence was strongly associated with age and was higher in women than in men. Few exceptions notwithstanding, the literature as a whole (and including AD) is consistent with a strong influence of cognitive status on prevalence of $A \beta$ positivity with PET. 


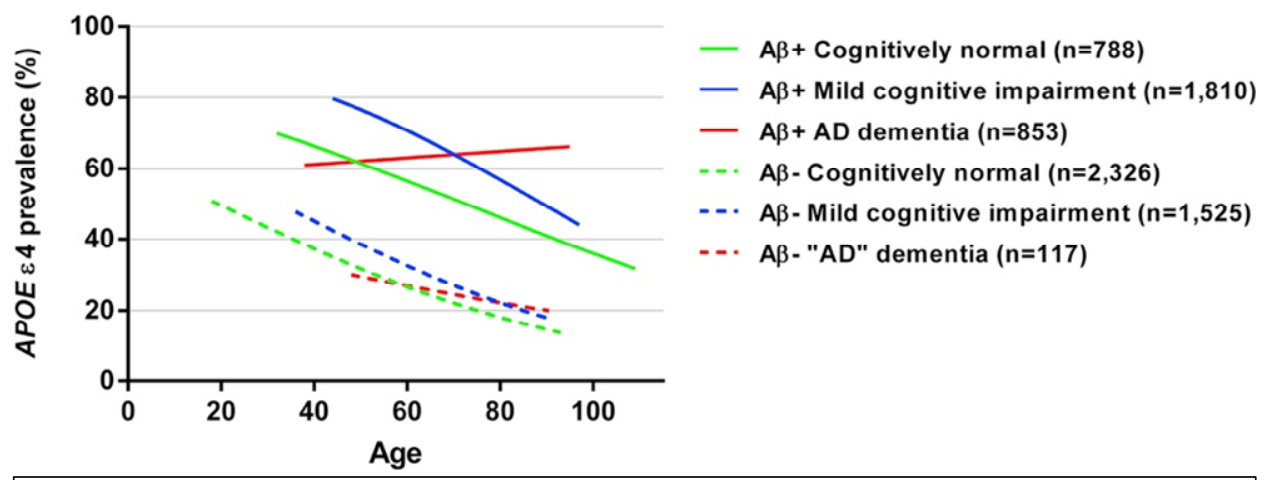

Figure 3. Prevalence of $A P O E \& 4$ positivity by age, diagnosis, and $A \beta$ status. Curves were plotted using the point estimates generated by generalized estimating equations and are within the age limits of the diagnostic groups. The models were adjusted for study (site) effect (from Mattsson et al., 2018).

Apolipoprotein-E genotype. Apolipoprotein E (ApoE) is a 299 amino-acid protein involved in lipid transport and metabolism in the periphery and in brain. ApoE plays a key role in neuronal maintenance and repair (for review see: (Mahley and Huang 2006)). The APOE gene, found on chromosome 19, has three common isoforms: $\varepsilon 2$ (5\%-10\% allele frequency), $\varepsilon 3$ (allele frequency $65 \%-70 \%)$ and $\varepsilon 4$ (15\%-20\%). The $\varepsilon 4$ allele (APOE $\varepsilon 4$ ) is by far the strongest genetic risk factor for sporadic $A D$, associated with a 3-fold increased risk in heterozygotes and up to a 15-fold increased risk of AD in homozygotes (Farrer et al., 1997), while APOE $\varepsilon 2$ may be protective. The $\varepsilon 4$-encoded $E 4$ isoform of ApoE has been implicated in multiple aspects of AD pathogenesis, including $A \beta$ fibrillization and clearance (Mahley and Huang 2006). Autopsy studies have demonstrated an increased likelihood of AD pathology in cognitively normal individuals who are APOE $\varepsilon 4$ carriers (Kok et al., 2009). Similarly, PiB-PET studies have found that $A P O E \& 4$ genotype is associated with higher PiB retention in cognitively normal elderly in a dose-dependent manner (Jack et al., 2015, Morris et al., 2010, Reiman et al., 2009), and APOE $\varepsilon 4$ carriers are more than twice as likely to convert from $\mathrm{PiB}(-)$ to $\mathrm{PiB}(+)$ over time (Vlassenko et al., 2011). Additionally, on average, $A P O E \varepsilon 4$ carriers have been show to develop amyloid pathology at an earlier age and demonstrate faster accumulation over time (Mishra et al., 2018). Conversely, APOE $\varepsilon 2$ has been associated with lower PiB retention in normal elderly (Grothe et al., 2017b, Morris et al., 2010). MCl patients who are APOE $\varepsilon 4$ carriers consistently show higher $\mathrm{PiB}$ retention than $\mathrm{MCl}$ non-carriers, though this is at least in part because the presence of $A P O E \& 4$ increases the likelihood that $\mathrm{MCl}$ symptoms are due to underlying $\mathrm{AD}$ 
(Kemppainen et al., 2007, Rowe et al., 2007). Findings in AD patients have been mixed, with some studies demonstrating increased PiB retention in APOE $\varepsilon 4$ carriers cross-sectionally (Drzezga et al., 2008) and longitudinally (Grimmer et al., 2010), while other studies did not find differences between APOE \&4 carriers and non-carriers in AD (Klunk et al., 2004b, Rabinovici et al., 2010, Rowe et al., 2007). However, in a recent study of APOE \&4 prevalence in A $\beta$-positive individuals across the $A D$ spectrum, it was demonstrated that the prevalence of APOE $\varepsilon 4$ was $66 \%$ in $\mathrm{AD}, 64 \%$ in $\mathrm{MCl}$, and $51 \%$ in cognitively normal, and that the prevalence decreased with advancing age in cognitively normal and MCI but not in AD (Mattsson et al., 2018, Figure XX). CSF $A \beta 42$ concentration is lower in APOE \&4 carriers but this is simply explained by the higher prevalence of $A \beta$ positivity as determined by $A \beta$ PET in such individuals and there is no constitutional effect of $A P O E$ genotype on CSF $A \beta 42$ levels in age groups that are definitely in pre-amyloid ages (below 40 years of age) (Lautner et al., 2014).

\section{$A \beta$ relationship to cognition}

Correlation with cognition within normal controls. Studies of cross-sectional associations between $A \beta$ imaging and cognitive measures have investigated whether presence or degree of $A \beta$ deposition accounts for some degree of individual differences in pre-symptomatic states or subtle pre-clinical cognitive deficits. The literature has been mixed on this question, with some studies finding small associations (Petersen et al., 2016, Pike et al., 2011, Rentz et al., 2011) and some finding none (Nebes et al., 2013, Rowe et al., 2010, Storandt et al., 2009). Addressing the equivocal state of findings, a 2013 meta-analysis by Hedden et al (2013) synthesized data from 34 independent studies across 3,495 NC participants using PET, CSF, plasma and histopathology measures of $A \beta$. They reported significant associations with episodic memory, executive functions and global measures of cognition; however, effect sizes were small ( $r=.05$ to .12), the largest being associations with episodic memory. Working memory, processing speed, visuospatial function and semantic memory did not have significant relationships to $A \beta$ burden. A more recent meta-analysis, synthesizing data across a larger pooled sample ( $n=5005$ across 30 cross-sectional datasets) and using studies of PET or CSF, Baker et al. (2017) found associations across a broader array of domains: global cognition, visuospatial function, 
processing speed, episodic memory and executive functions. Consistent with the Hedden et al. meta-analysis, cross-sectional association effect sizes were small, ranging from Cohen's $d=.15$ (episodic memory) to $d=.32$ (global cognition). A third and most recent meta-analysis (Jansen et al., 2018) examined $A \beta$ positivity (via imaging and CSF), and its association with low episodic verbal memory and Mini Mental State Exam (MMSE) scores in CN and $\mathrm{MCl}$ participants. Among $\mathrm{n}=2908$ persons with normal cognition, amyloid positivity was associated with low memory scores only after age 70; there was no association with low MMSE scores. All three metaanalyses support a general consensus that cross-sectional relationships between $A \beta$ deposition and cognitive abilities among healthy older adults is small to very small, measurable only with sufficient power. It is important, however, to keep in mind the obvious presence of selection bias in these cross-sectional studies. The requirement for "normal cognition" does two things to bias these studies: 1) it selects against those people who are susceptible to the negative effects of $A \beta$ on cognition and 2) it compresses the range of cognitive scores that can be correlated with $A \beta$ deposition.

Prediction of cognitive change. Compared to cross-sectional associations, there is clearer evidence and consensus that $A \beta$ deposition on imaging is a predictor of future change in cognition. In studies of diagnostic change, this is most evidenced in studies of $\mathrm{MCl}$ reporting presence and degree of $A \beta$ predicts higher risk for, and shorter time to, progression to $A D$ (Huijbers et al., 2015, Jack et al., 2010, Koivunen et al., 2011, Okello et al., 2009, Wolk et al., 2009, Zhang and Shen 2012). Among older adults with NC, progression to $\mathrm{MCl}$ is higher with baseline presence of $A \beta$ (Petersen et al., 2016, Roberts et al., 2018, Rowe et al., 2013, Vos et al., 2013). For example, in a recent large population-based study including $n=1377$ older adults without cognitive impairment, incident amnestic $\mathrm{MCl}$ risk associated with $A \beta$-positivity was more than twice that with $A \beta$-negativity (Hazard Ratio (HR) 2.26; Roberts et al., 2018). While significant, the authors note this is a smaller effect on clinical progression compared to clinic- or volunteer-based CN cohorts (e.g., OR of 4.8 reported by Rowe et al, 2013; HRs of 4.6-33.8 reported by Vos et al., 2013), which often report, or enrich with, a higher proportion of APOE e4 carriers (Petersen et al., 2016, Rowe et al., 2013). As with prevalence estimates, this 
underscores the importance of study setting and selection variables on clinical progression risk associated with $A \beta$-positive imaging.

Baseline $A \beta$-positive scans in $\mathrm{CN}$ cohorts also predict greater decline over time on cognitive test scores (Donohue et al., 2017, Mormino et al., 2014a, Petersen et al., 2016, Vemuri et al., 2015, Zhao et al., 2018). The decline has been reported over a range of follow-up times, e.g. median of 2 years (Mormino et al., 2014a) to mean of 12 years (Zhao et al., 2018), and across both memory, e.g., (Resnick et al., 2010) and nonmemory domains, e.g., (Papp et al., 2016, Zhao et al., 2018). An example of $A \beta-$ associated executive function decline is shown in Figure $x$, depicting worse (higher)

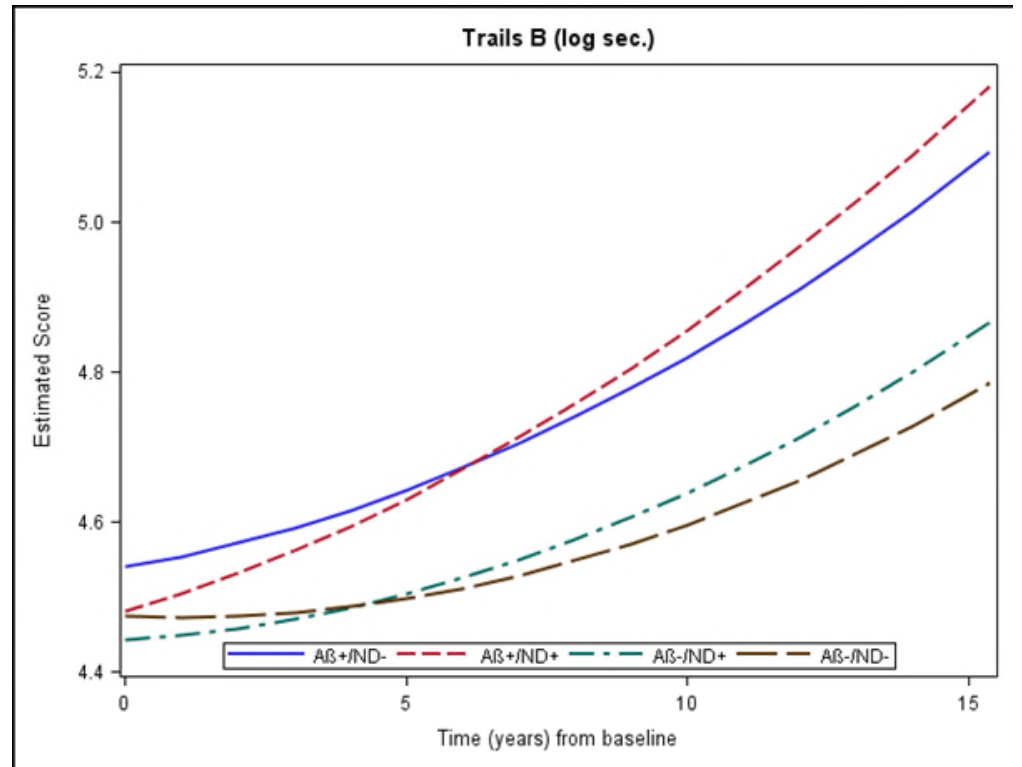

Figure 4. Performance (higher scores $=$ decline) on Trail Making Test $B$, an executive function measure, over 15 years in $n=175$ oldest-old adults (mean age at time of imaging, 86 years) without dementia, by biomarker group. $A \beta=$ amyloid-beta; $N D=$ neurodegeneration, defined by hippocampal volume. From (Zhao et al., 2018).

scores on Trail Making Test B over 15 years in an oldest old cohort (Zhao et al., 2018). Aßassociated cognitive decline is moderated (i.e., further enhanced) by presence of the APOE*4 allele (Lim et al., 2015); SCD (Vogel et al., 2017); and neurodegeneration markers. e.g., (Mormino et al., 2014b). The 2017 Baker et al. meta-analysis aggregated cognitive decline data across $2584 \mathrm{CN}$ participants from 14 studies over an average of approximately 5 years. A $\beta$ related decline was observed in episodic memory, semantic memory, visuospatial function, and global cognition; effect sizes ranged from $d=.24$ (episodic memory) to .30 (global cognition). Thus, these meta-analytic estimates of multi-domain cognitive decline suggest relatively small though reliable effects associated with $A \beta$ deposition in healthy $C N$ older adults. Low CSF A 42 predicts dementia in $\mathrm{MCl}$ patients over 10 years with a positive predictive value of $81 \%$, reaching 94\% if combined with CSF tau markers (Buchhave et al., 2012).

Longitudinal $A B$ imaging and cognitive change. A small number of studies to date have examined how $A \beta$ accumulation corresponds directly to cognitive decline. Using clinical 
progression as a measure of cognitive change, Koivunen et al. (2011) found no correspondence between change in $A \beta$ deposition (regional PiB retention) over two years and progression to $A D$ in a small $\mathrm{MCl}$ sample $(n=25)$. In contrast, examining change in cognitive test scores, Villemagne et al. (2011) followed NC, MCl and AD participants out to 38 months and reported correlations of change in $A \beta$ to change in cognition of $r=-.27$ (MMSE) to $r=-.39$ (non-memory tests), across diagnostic categories. The largest correlation of change-to-change was observed in the $\mathrm{MCl}$ group alone ( $r=-.51$, observed with decline in non-memory tests), a clinical stage which may represent fastest rate of change both in $A \beta$ accumulation (before plateau effects) and cognitive test performance (before floor effects).

Landau et al. (2018) examined $A \beta$ accumulation in relation to cognitive test change over time in the $A D N I$ dataset. In 142 baseline cognitively normal, $A \beta$-negative participants, the authors found that florbetapir accumulation (i.e., a positive slope over time) was associated with greater memory decline over 2 to 6 years. Notably, the majority of participants remained cognitively normal and florbetapir-negative over the follow up, indicating subtle but detectable memory changes accompanying $A \beta$ accumulation before widespread cortical distribution (i.e., $A \beta$ positivity).

\section{Summary}

Fluid and PET biomarkers are robust in vivo measurements of $A \beta$ that have been validated in relation to neuropathology and are critical to the definition of $A D$ in the recent NIAAA AD Research Framework. Standardization of multiple measurements is in progress and holds promise for multisite studies, cross-study comparisons, clinical trials, and clinical use. Age, ApoE4 status, and cognitively impaired clinical status are known risk factors for increased $A \beta$ deposition. In line with work on therapeutic treatments for AD that aim to detect the earliest stages of pathology, recent work has focused increasingly on early detection $A \beta$ burden and the accompanying clinical consequences of this deposition. 
1. Andreasen N., Hesse C., Davidsson P., Minthon L., Wallin A., Winblad B., Vanderstichele H., Vanmechelen E., Blennow K., 1999. Cerebrospinal fluid beta-amyloid(1-42) in Alzheimer disease: differences between early- and late-onset Alzheimer disease and stability during the course of disease. Arch Neurol 56, 673-80.

2. Annus T., Wilson L.R., Hong Y.T., Acosta-Cabronero J., Fryer T.D., Cardenas-Blanco A., Smith R., Boros I., Coles J.P., Aigbirhio F.I., Menon D.K., Zaman S.H., Nestor P.J., Holland A.J., 2016. The pattern of amyloid accumulation in the brains of adults with Down syndrome. Alzheimers Dement 12, 538-45. doi: 10.1016/j.jalz.2015.07.490

3. Ashton N.J., Scholl M., Heurling K., Gkanatsiou E., Portelius E., Hoglund K., Brinkmalm G., Hye A., Blennow K., Zetterberg H., 2018. Update on biomarkers for amyloid pathology in Alzheimer's disease. Biomark Med 12, 799-812. doi: 10.2217/bmm-2017-0433

4. Bacskai B.J., Frosch M.P., Freeman S.H., Raymond S.B., Augustinack J.C., Johnson K.A., Irizarry M.C., Klunk W.E., Mathis C.A., Dekosky S.T., Greenberg S.M., Hyman B.T., Growdon J.H., 2007. Molecular imaging with Pittsburgh Compound B confirmed at autopsy: a case report. Arch Neurol 64, 431-4.

5. Baker J.E., Lim Y.Y., Pietrzak R.H., Hassenstab J., Snyder P.J., Masters C.L., Maruff P., 2017. Cognitive impairment and decline in cognitively normal older adults with high amyloid- $\beta$ : A meta-analysis. Alzheimer's \& Dementia: Diagnosis, Assessment \& Disease Monitoring 6, 108121.

6. Baker S.L., DeCarli C. (2018) personal communication.

7. Bateman R.J., Xiong C., Benzinger T.L., Fagan A.M., Goate A., Fox N.C., Marcus D.S., Cairns N.J., Xie X., Blazey T.M., Holtzman D.M., Santacruz A., Buckles V., Oliver A., Moulder K., Aisen P.S., Ghetti B., Klunk W.E., McDade E., Martins R.N., Masters C.L., Mayeux R., Ringman J.M., Rossor M.N., Schofield P.R., Sperling R.A., Salloway S., Morris J.C., 2012. Clinical and biomarker changes in dominantly inherited Alzheimer's disease. N Engl J Med 367, 795-804. doi: 10.1056/NEJMoa1202753

8. Battle M.R., Buckley C.J., Smith A., Van Laere K., Vandenberghe R., Lowe V.J., 2016. Utility of PMOD image quantification software for processing [11C]PiB and [18F]flutemetamol images for SUVR quantitation on the Centiloid scale. Alzheimer's \& Dementia 12, P126.

9. Benzinger T.L., Blazey T., Jack C.R., Jr., Koeppe R.A., Su Y., Xiong C., Raichle M.E., Snyder A.Z., Ances B.M., Bateman R.J., Cairns N.J., Fagan A.M., Goate A., Marcus D.S., Aisen P.S., Christensen J.J., Ercole L., Hornbeck R.C., Farrar A.M., Aldea P., Jasielec M.S., Owen C.J., Xie X., Mayeux R., Brickman A., McDade E., Klunk W., Mathis C.A., Ringman J., Thompson P.M., Ghetti B., Saykin A.J., Sperling R.A., Johnson K.A., Salloway S., Correia S., Schofield P.R., Masters C.L., Rowe C., Villemagne V.L., Martins R., Ourselin S., Rossor M.N., Fox N.C., Cash D.M., Weiner 
M.W., Holtzman D.M., Buckles V.D., Moulder K., Morris J.C., 2013. Regional variability of imaging biomarkers in autosomal dominant Alzheimer's disease. Proc Natl Acad Sci U S A 110, E4502-9. doi: 10.1073/pnas.1317918110

10. Bittner T., Zetterberg H., Teunissen C.E., Ostlund R.E., Jr., Militello M., Andreasson U., Hubeek I., Gibson D., Chu D.C., Eichenlaub U., Heiss P., Kobold U., Leinenbach A., Madin K., Manuilova E., Rabe C., Blennow K., 2016. Technical performance of a novel, fully automated electrochemiluminescence immunoassay for the quantitation of beta-amyloid (1-42) in human cerebrospinal fluid. Alzheimers Dement 12, 517-26. doi: 10.1016/j.jalz.2015.09.009

11. Blennow K., Mattsson N., Scholl M., Hansson O., Zetterberg H., 2015. Amyloid biomarkers in Alzheimer's disease. Trends Pharmacol Sci 36, 297-309. doi:

10.1016/j.tips.2015.03.002

12. Bourgeat P., Chételat G., Villemagne V.L., Fripp J., Raniga P., Pike K., Acosta O., Szoeke C., Ourselin S., Ames D., Ellis K.A., Martins R.N., Masters C.L., Rowe C.C., O. S., Group. A.R., 2010. Beta-amyloid burden in the temporal neocortex is related to hippocampal atrophy in elderly subjects without dementia. Neurology 74, 121-7.

13. Braak H., Braak E., 1991. Neuropathological staging of Alzheimer-related changes. Acta Neuropathologica 82, 239-259.

14. Braak H., Braak E., 1997. Frequency of stages of Alzheimer-related lesions in different age categories. Neurobiology of Aging 18, 351-357.

15. Buchhave P., Minthon L., Zetterberg H., Wallin A.K., Blennow K., Hansson O., 2012.

Cerebrospinal fluid levels of beta-amyloid 1-42, but not of tau, are fully changed already 5 to 10 years before the onset of Alzheimer dementia. Arch Gen Psychiatry 69, 98-106. doi:

10.1001/archgenpsychiatry.2011.155

16. Buckner R.L., Snyder A.Z., Shannon B.J., LaRossa G., Sachs R., Fotenos A.F., Sheline Y.I., Klunk W.E., Mathis C.A., Morris J.C., Mintun M.A., 2005. Molecular, structural, and functional characterization of Alzheimer's disease: evidence for a relationship between default activity, amyloid, and memory. J Neurosci 25, 7709-17.

17. Burack M.A., Hartlein J., Flores H.P., Taylor-Reinwald L., Perlmutter J.S., Cairns N.J., 2010. In vivo amyloid imaging in autopsy-confirmed Parkinson disease with dementia. Neurology 74, 77-84.

18. Cairns N.J., Ikonomovic M.D., Benzinger T., Storandt M., Fagan A.M., Shah A., Schmidt R.E., Perry A., Reinwald L.T., Carter D., Felton A., Holtzman D.M., Mintun M.A., Klunk W.E., Morris J.C., 2009. Absence of PIttsburgh Compound B Detection of CerebralAmyloid Beta in a Patient With Clinical, Cognitive, and Cerebrospinal FluidMarkers of Alzheimer Disease. Arch Neurol 66, 1557-1562.

19. Clark C.M., Pontecorvo M.J., Beach T.G., Bedell B.J., Coleman R.E., Doraiswamy P.M., Fleisher A.S., Reiman E.M., Sabbagh M.N., Sadowsky C.H., Schneider J.A., Arora A., Carpenter A.P., Flitter M.L., Joshi A.D., Krautkramer M.J., Lu M., Mintun M.A., Skovronsky D.M., 2012. Cerebral PET with florbetapir compared with neuropathology at autopsy for detection of neuritic amyloid-beta plaques: a prospective cohort study. Lancet Neurol 11,669-78. doi: 10.1016/S1474-4422(12)70142-4

20. Clark C.M., Schneider J.A., Bedell B.J., Beach T.G., Bilker W.B., Mintun M.A., Pontecorvo M.J., Hefti F., Carpenter A.P., Flitter M.L., Krautkramer M.J., Kung H.F., Coleman R.E., Doraiswamy P.M., Fleisher A.S., Sabbagh M.N., Sadowsky C.H., Reiman E.P., Zehntner S.P., 
Skovronsky D.M., 2011. Use of florbetapir-PET for imaging beta-amyloid pathology. JAMA : the journal of the American Medical Association 305, 275-83. doi: 10.1001/jama.2010.2008

21. Cohen A.D., Mowrey W., Weissfeld L.A., Aizenstein H.J., McDade E., Mountz J.M., Nebes R.D., Saxton J.A., Snitz B., Dekosky S., Williamson J., Lopez O.L., Price J.C., Mathis C.A., Klunk W.E., 2013. Classification of amyloid-positivity in controls: comparison of visual read and quantitative approaches. Neuroimage 71, 207-15. doi: 10.1016/j.neuroimage.2013.01.015 22. Cohen A.D., Rabinovici G.D., Mathis C.A., Jagust W.J., Klunk W.E., Ikonomovic M.D., 2012. Using Pittsburgh Compound $B$ for in vivo PET imaging of fibrillar amyloid-beta. Advances in pharmacology 64, 27-81. doi: 10.1016/B978-0-12-394816-8.00002-7

23. Curtis C., Gamez J.E., Singh U., Sadowsky C.H., Villena T., Sabbagh M.N., Beach T.G., Duara R., Fleisher A.S., Frey K.A., Walker Z., Hunjan A., Holmes C., Escovar Y.M., Vera C.X., Agronin M.E., Ross J., Bozoki A., Akinola M., Shi J., Vandenberghe R., Ikonomovic M.D., Sherwin P.F., Grachev I.D., Farrar G., Smith A.P., Buckley C.J., McLain R., Salloway S., 2015. Phase 3 trial of flutemetamol labeled with radioactive fluorine 18 imaging and neuritic plaque density. JAMA Neurol 72, 287-94. doi: 10.1001/jamaneurol.2014.4144

24. Devanand D.P., Mikhno A., Pelton G.H., Cuasay K., Pradhaban G., Dileep Kumar J.S., Upton N., Lai R., Gunn R.N., Libri V., Liu X., van Heertum R., Mann J.J., Parsey R.V., 2010. Pittsburgh compound B (11C-PIB) and fluorodeoxyglucose (18 F-FDG) PET in patients with Alzheimer disease, mild cognitive impairment, and healthy controls. J Geriatr Psychiatry Neurol 23, 185-98. doi: 10.1177/0891988710363715

25. Donohue M.C., Sperling R.A., Petersen R., Sun C.-K., Weiner M.W., Aisen P.S., 2017. Association between elevated brain amyloid and subsequent cognitive decline among cognitively normal persons. Jama 317, 2305-2316.

26. Drzezga A., Grimmer T., Henriksen G., Stangier I., Perneczky R., Diehl-Schmid J., Mathis C.A., Klunk W.E., Price J., Dekosky S., Wester H.J., Schwaiger M., Kurz A., 2008. Imaging of amyloid plaques and cerebral glucose metabolism in semantic dementia and Alzheimer's disease. Neuroimage 39, 619-33.

27. Dubois B., Hampel H., Feldman H.H., Scheltens P., Aisen P., Andrieu S., Bakardjian H., Benali H., Bertram L., Blennow K., Broich K., Cavedo E., Crutch S., Dartigues J.F., Duyckaerts C., Epelbaum S., Frisoni G.B., Gauthier S., Genthon R., Gouw A.A., Habert M.O., Holtzman D.M., Kivipelto M., Lista S., Molinuevo J.L., O'Bryant S.E., Rabinovici G.D., Rowe C., Salloway S., Schneider L.S., Sperling R., Teichmann M., Carrillo M.C., Cummings J., Jack C.R., Jr., Proceedings of the Meeting of the International Working G., the American Alzheimer's Association on "The Preclinical State of A.D., July, Washington Dc U.S.A., 2016. Preclinical Alzheimer's disease: Definition, natural history, and diagnostic criteria. Alzheimers Dement 12, 292-323. doi: 10.1016/j.jalz.2016.02.002

28. Edison P., Rowe C.C., Rinne J.O., Ng S., Ahmed I., Kemppainen N., Villemagne V.L., O'Keefe G., Nagren K., Chaudhuri R., Masters C.L., Brooks D.J., 2008. Amyloid load in Parkinson's disease dementia and Lewy Body dementia measured with [11C]PIB-PET. J Neurol Neurosurg Psychiatry, jnnp.2007.127878. doi: 10.1136/jnnp.2007.127878

29. Engler H., Santillo A.F., Wang S.X., Lindau M., Savitcheva I., Nordberg A., Lannfelt L., Langstrom B., Kilander L., 2007. In vivo amyloid imaging with PET in frontotemporal dementia. Eur J Nucl Med Mol Imaging. 
30. Ewers M., Insel P., Jagust W.J., Shaw L., Trojanowski J.Q., Aisen P., Petersen R.C., Schuff N., Weiner M.W., Alzheimer's Disease Neuroimaging I., 2012. CSF biomarker and PIB-PETderived beta-amyloid signature predicts metabolic, gray matter, and cognitive changes in nondemented subjects. Cereb Cortex 22, 1993-2004. doi: 10.1093/cercor/bhr271

31. Fagan A.M., Head D., Shah A.R., Marcus D., Mintun M., Morris J.C., Holtzman D.M., 2009. Decreased cerebrospinal fluid Abeta(42) correlates with brain atrophy in cognitively normal elderly. Annals of Neurology 65, 176-83. doi: 10.1002/ana.21559

32. Fagan A.M., Shaw L.M., Xiong C., Vanderstichele H., Mintun M.A., Trojanowski J.Q., Coart E., Morris J.C., Holtzman D.M., 2011. Comparison of analytical platforms for cerebrospinal fluid measures of beta-amyloid 1-42, total tau, and p-tau181 for identifying Alzheimer disease amyloid plaque pathology. Arch Neurol 68, 1137-44. doi: 10.1001/archneurol.2011.105

33. Farrer L.A., Cupples L.A., Haines J.L., Hyman B., Kukull W.A., Mayeux R., Myers R.H., Pericak-Vance M.A., Risch N., van D.M., 1997. Effects of age, sex, and ethnicity on the association between apolipoprotein E genotype and Alzheimer disease. A meta-analysis. APOE and Alzheimer Disease Meta Analysis Consortium [see comments]. Jama 278, 1349-1356.

34. Fleisher A.S., Chen K., Liu X., Roontiva A., Thiyyagura P., Ayutyanont N., Joshi A.D., Clark C.M., Mintun M.A., Pontecorvo M.J., Doraiswamy P.M., Johnson K.A., Skovronsky D.M., Reiman E.M., 2011. Using Positron Emission Tomography and Florbetapir F 18 to Image Cortical Amyloid in Patients With Mild Cognitive Impairment or Dementia Due to Alzheimer Disease. Arch Neurol.

35. Forsberg A., Almkvist O., Engler H., Wall A., Langstrom B., Nordberg A., 2010. High PIB retention in Alzheimer's disease is an early event with complex relationship with CSF biomarkers and functional parameters. Curr Alzheimer Res 7, 56-66.

36. Gomperts S.N., Rentz D.M., Moran E., Becker J.A., Locascio J.J., Klunk W.E., Mathis C.A., Elmaleh D.R., Shoup T., Fischman A.J., Hyman B.T., Growdon J.H., Johnson K.A. (2008) Imaging amyloid deposition in Lewy body diseases. pp. 903-910

37. Greenberg S.M., Grabowski T., Gurol M.E., Skehan M.E., Nandigam R.N., Becker J.A., Garcia-Alloza M., Prada C., Frosch M.P., Rosand J., Viswanathan A., Smith E.E., Johnson K.A., 2008. Detection of isolated cerebrovascular beta-amyloid with Pittsburgh compound B. Ann Neurol 64, 587-91.

38. Grimmer T., Tholen S., Yousefi B.H., Alexopoulos P., Forschler A., Forstl H., Henriksen G., Klunk W.E., Mathis C.A., Perneczky R., Sorg C., Kurz A., Drzezga A., 2010. Progression of cerebral amyloid load is associated with the apolipoprotein E epsilon4 genotype in Alzheimer's disease. Biol Psychiatry 68, 879-84. doi: 10.1016/j.biopsych.2010.05.013

39. Grothe M.J., Barthel H., Sepulcre J., Dyrba M., Sabri O., Teipel S.J., 2017a. In vivo staging of regional amyloid deposition. Neurology. doi: 10.1212/WNL.0000000000004643

40. Grothe M.J., Villeneuve S., Dyrba M., Bartres-Faz D., Wirth M., Alzheimer's Disease Neuroimaging I., 2017b. Multimodal characterization of older APOE2 carriers reveals selective reduction of amyloid load. Neurology 88, 569-576. doi: 10.1212/WNL.0000000000003585 41. Handen B.L., Cohen A.D., Channamalappa U., Bulova P., Cannon S.A., Cohen W.I., Mathis C.A., Price J.C., Klunk W.E., 2012. Imaging brain amyloid in nondemented young adults with Down syndrome using Pittsburgh compound B. Alzheimer's \& dementia : the journal of the Alzheimer's Association 8, 496-501. doi: 10.1016/j.jalz.2011.09.229 
42. Hansson O., Zetterberg H., Buchhave P., Andreasson U., Londos E., Minthon L., Blennow K., 2007. Prediction of Alzheimer's disease using the CSF Abeta42/Abeta40 ratio in patients with mild cognitive impairment. Dement Geriatr Cogn Disord 23, 316-20. doi: 10.1159/000100926

43. Hansson O., Zetterberg H., Buchhave P., Londos E., Blennow K., Minthon L., 2006. Association between CSF biomarkers and incipient Alzheimer's disease in patients with mild cognitive impairment: a follow-up study. Lancet Neurol 5, 228-34.

44. Hedden T., Oh H., Younger A.P., Patel T.A., 2013. Meta-analysis of amyloid-cognition relations in cognitively normal older adults. Neurology 80, 1341-1348.

45. Hedden T., Van Dijk K.R., Becker J.A., Mehta A., Sperling R.A., Johnson K.A., Buckner R.L., 2009. Disruption of functional connectivity in clinically normal older adults harboring amyloid burden. J Neurosci 29, 12686-94.

46. Huijbers W., Mormino E.C., Schultz A.P., Wigman S., Ward A.M., Larvie M., Amariglio R.E., Marshall G.A., Rentz D.M., Johnson K.A., 2015. Amyloid- $\beta$ deposition in mild cognitive impairment is associated with increased hippocampal activity, atrophy and clinical progression. Brain 138, 1023-1035.

47. Hyman B.T., Gomez-Isla T., 1997. The natural history of Alzheimer neurofibrillary tangles and amyloid deposits. Neurobiology of Aging 18, 386-7discussion.

48. Hyman B.T., Phelps C.H., Beach T.G., Bigio E.H., Cairns N.J., Carrillo M.C., Dickson D.W., Duyckaerts C., Frosch M.P., Masliah E., Mirra S.S., Nelson P.T., Schneider J.A., Thal D.R., Thies B., Trojanowski J.Q., Vinters H.V., Montine T.J., 2012. National Institute on Aging-Alzheimer's Association guidelines for the neuropathologic assessment of Alzheimer's disease. Alzheimers Dement 8, 1-13. doi: 10.1016/j.jalz.2011.10.007

49. Ikonomovic M.D., Abrahamson E.E., Price J.C., Hamilton R.L., Mathis C.A., Paljug W.R., Debnath M.L., Cohen A.D., Mizukami K., DeKosky S.T., Lopez O.L., Klunk W.E., 2012. Early AD pathology in a [C-11] PiB-negative case: a PiB-amyloid imaging, biochemical, and immunohistochemical study. Acta Neuropathologica 123, 433-47. doi: 10.1007/s00401-0120943-2

50. Ikonomovic M.D., Klunk W.E., Abrahamson E.E., Mathis C.A., Price J.C., Tsopelas N.D., Lopresti B.J., Ziolko S., Bi W., Paljug W.R., Debnath M.L., Hope C.E., Isanski B.A., Hamilton R.L., DeKosky S.T., 2008. Post-mortem correlates of in vivo PiB-PET amyloid imaging in a typical case of Alzheimer's disease. Brain 131, 1630-45.

51. Insel P.S., Ossenkoppele R., Gessert D., Jagust W., Landau S., Hansson O., Weiner M.W., Mattsson N., Alzheimer's Disease Neuroimaging I., 2017. Time to Amyloid Positivity and Preclinical Changes in Brain Metabolism, Atrophy, and Cognition: Evidence for Emerging Amyloid Pathology in Alzheimer's Disease. Front Neurosci 11, 281. doi:

10.3389/fnins.2017.00281

52. Jack C.R., Jr., Bennett D.A., Blennow K., Carrillo M.C., Dunn B., Haeberlein S.B., Holtzman D.M., Jagust W., Jessen F., Karlawish J., Liu E., Molinuevo J.L., Montine T., Phelps C., Rankin K.P., Rowe C.C., Scheltens P., Siemers E., Snyder H.M., Sperling R., Contributors, 2018. NIA-AA Research Framework: Toward a biological definition of Alzheimer's disease. Alzheimers Dement 14, 535-562. doi: 10.1016/j.jalz.2018.02.018

53. Jack C.R., Jr., Knopman D.S., Jagust W.J., Petersen R.C., Weiner M.W., Aisen P.S., Shaw L.M., Vemuri P., Wiste H.J., Weigand S.D., Lesnick T.G., Pankratz V.S., Donohue M.C., Trojanowski J.Q., 2013. Tracking pathophysiological processes in Alzheimer's disease: an 
updated hypothetical model of dynamic biomarkers. Lancet neurology 12, 207-16. doi: 10.1016/S1474-4422(12)70291-0

54. Jack C.R., Jr., Lowe V.J., Senjem M.L., Weigand S.D., Kemp B.J., Shiung M.M., Knopman D.S., Boeve B.F., Klunk W.E., Mathis C.A., Petersen R.C., 2008. 11C PiB and structural MRI provide complementary information in imaging of Alzheimer's disease and amnestic mild cognitive impairment. Brain 131, 665-80.

55. Jack C.R., Jr., Wiste H.J., Vemuri P., Weigand S.D., Senjem M.L., Zeng G., Bernstein M.A., Gunter J.L., Pankratz V.S., Aisen P.S., Weiner M.W., Petersen R.C., Shaw L.M., Trojanowski J.Q., Knopman D.S., 2010. Brain beta-amyloid measures and magnetic resonance imaging atrophy both predict time-to-progression from mild cognitive impairment to Alzheimer's disease. Brain : a journal of neurology 133, 3336-48. doi: 10.1093/brain/awq277

56. Jack C.R., Jr., Wiste H.J., Weigand S.D., Knopman D.S., Vemuri P., Mielke M.M., Lowe V., Senjem M.L., Gunter J.L., Machulda M.M., Gregg B.E., Pankratz V.S., Rocca W.A., Petersen R.C., 2015. Age, Sex, and APOE epsilon4 Effects on Memory, Brain Structure, and beta-Amyloid Across the Adult Life Span. JAMA Neurol 72, 511-9. doi: 10.1001/jamaneurol.2014.4821 57. Jack C.R., Jr., Wiste H.J., Weigand S.D., Therneau T.M., Knopman D.S., Lowe V., Vemuri P., Mielke M.M., Roberts R.O., Machulda M.M., Senjem M.L., Gunter J.L., Rocca W.A., Petersen R.C., 2017a. Age-specific and sex-specific prevalence of cerebral beta-amyloidosis, tauopathy, and neurodegeneration in cognitively unimpaired individuals aged $50-95$ years: a crosssectional study. Lancet Neurol 16, 435-444. doi: 10.1016/S1474-4422(17)30077-7

58. Jack C.R., Jr., Wiste H.J., Weigand S.D., Therneau T.M., Lowe V.J., Knopman D.S., Gunter J.L., Senjem M.L., Jones D.T., Kantarci K., Machulda M.M., Mielke M.M., Roberts R.O., Vemuri P., Reyes D.A., Petersen R.C., 2017b. Defining imaging biomarker cut points for brain aging and Alzheimer's disease. Alzheimers Dement 13, 205-216. doi: 10.1016/j.jalz.2016.08.005

59. Janelidze S., Stomrud E., Palmqvist S., Zetterberg H., van Westen D., Jeromin A., Song L., Hanlon D., Tan Hehir C.A., Baker D., Blennow K., Hansson O., 2016. Plasma beta-amyloid in Alzheimer's disease and vascular disease. Sci Rep 6, 26801. doi: 10.1038/srep26801 60. Jansen W.J., Ossenkoppele R., Knol D.L., Tijms B.M., Scheltens P., Verhey F.R., Visser P.J., Aalten P., Aarsland D., Alcolea D., 2015a. Prevalence of cerebral amyloid pathology in persons without dementia: a meta-analysis. Jama 313, 1924-1938.

61. Jansen W.J., Ossenkoppele R., Knol D.L., Tijms B.M., Scheltens P., Verhey F.R., Visser P.J., Amyloid Biomarker Study G., Aalten P., Aarsland D., Alcolea D., Alexander M., Almdahl I.S., Arnold S.E., Baldeiras I., Barthel H., van Berckel B.N., Bibeau K., Blennow K., Brooks D.J., van Buchem M.A., Camus V., Cavedo E., Chen K., Chetelat G., Cohen A.D., Drzezga A., Engelborghs S., Fagan A.M., Fladby T., Fleisher A.S., van der Flier W.M., Ford L., Forster S., Fortea J., Foskett N., Frederiksen K.S., Freund-Levi Y., Frisoni G.B., Froelich L., Gabryelewicz T., Gill K.D., Gkatzima O., Gomez-Tortosa E., Gordon M.F., Grimmer T., Hampel H., Hausner L., Hellwig S., Herukka S.K., Hildebrandt H., Ishihara L., Ivanoiu A., Jagust W.J., Johannsen P., Kandimalla R., Kapaki E., Klimkowicz-Mrowiec A., Klunk W.E., Kohler S., Koglin N., Kornhuber J., Kramberger M.G., Van Laere K., Landau S.M., Lee D.Y., de Leon M., Lisetti V., Lleo A., Madsen K., Maier W., Marcusson J., Mattsson N., de Mendonca A., Meulenbroek O., Meyer P.T., Mintun M.A., Mok V., Molinuevo J.L., Mollergard H.M., Morris J.C., Mroczko B., Van der Mussele S., Na D.L., Newberg A., Nordberg A., Nordlund A., Novak G.P., Paraskevas G.P., Parnetti L., Perera G., Peters O., Popp J., Prabhakar S., Rabinovici G.D., Ramakers I.H., Rami L., Resende de Oliveira C., Rinne J.O., 
Rodrigue K.M., Rodriguez-Rodriguez E., Roe C.M., Rot U., Rowe C.C., Ruther E., Sabri O., Sanchez-Juan P., Santana I., Sarazin M., Schroder J., Schutte C., Seo S.W., Soetewey F., Soininen H., Spiru L., Struyfs H., Teunissen C.E., Tsolaki M., Vandenberghe R., Verbeek M.M., Villemagne V.L., Vos S.J., van Waalwijk van Doorn L.J., Waldemar G., Wallin A., Wallin A.K., Wiltfang J., Wolk D.A., Zboch M., Zetterberg H., 2015b. Prevalence of cerebral amyloid pathology in persons without dementia: a meta-analysis. JAMA 313, 1924-38. doi: 10.1001/jama.2015.4668

62. Jansen W.J., Ossenkoppele R., Tijms B.M., Fagan A.M., Hansson O., Klunk W.E., Van Der Flier W.M., Villemagne V.L., Frisoni G.B., Fleisher A.S., 2018. Association of cerebral amyloid- $\beta$ aggregation with cognitive functioning in persons without dementia. JAMA psychiatry 75, 8495.

63. Johnson K., Gregas M., Becker J., Kinnecom C., Salat D., Moran E., Rosand J., Rentz D., Klunk W., Mathis C., DeKosky S., Fischman A., Greenberg S., 2007a. Amyloid imaging of cerebral amyloid angiopathy. J Nucl Med 48, 255P-a-.

64. Johnson K.A., Gregas M., Becker J.A., Kinnecom C., Salat D.H., Moran E.K., Smith E.E., Rosand J., Rentz D.M., Klunk W.E., Mathis C.A., Price J.C., Dekosky S.T., Fischman A.J., Greenberg S.M., 2007b. Imaging of amyloid burden and distribution in cerebral amyloid angiopathy. Ann Neurol.

65. Johnson K.A., Sperling R.A., Gidicsin C.M., Carmasin J.S., Maye J.E., Coleman R.E., Reiman E.M., Sabbagh M.N., Sadowsky C.H., Fleisher A.S., 2013. Florbetapir (F18-AV-45) PET to assess amyloid burden in Alzheimer's disease dementia, mild cognitive impairment, and normal aging. Alzheimer's \& Dementia 9, S72-S83.

66. Joshi A.D., Pontecorvo M.J., Clark C.M., Carpenter A.P., Jennings D.L., Sadowsky C.H., Adler L.P., Kovnat K.D., Seibyl J.P., Arora A., Saha K., Burns J.D., Lowrey M.J., Mintun M.A., Skovronsky D.M., Florbetapir F.S.I., 2012. Performance characteristics of amyloid PET with florbetapir F 18 in patients with alzheimer's disease and cognitively normal subjects. J Nucl Med 53, 378-84. doi: 10.2967/jnumed.111.090340

67. Kaneko N., Nakamura A., Washimi Y., Kato T., Sakurai T., Arahata Y., Bundo M., Takeda A., Niida S., Ito K., Toba K., Tanaka K., Yanagisawa K., 2014. Novel plasma biomarker surrogating cerebral amyloid deposition. Proc Jpn Acad Ser B Phys Biol Sci 90, 353-64.

68. Kemppainen N.M., Aalto S., Wilson I.A., Nagren K., Helin S., Bruck A., Oikonen V., Kailajarvi M., Scheinin M., Viitanen M., Parkkola R., Rinne J.O., 2007. PET amyloid ligand [11C]PIB uptake is increased in mild cognitive impairment. Neurology 68, 1603-6.

69. Klunk, Lopresti, Debnath, Huang, Shao, Lefterov, Koldamova, Ikonomovic, DeKosky, Mathis, 2005a. Low binding of the amyloid PET tracer, PIB, to transgenic PS1/APP mouse brain compared to human AD brain explained by Bmax. Alzheimer's \& Dementia: The Journal of the Alzheimer's Association 1, 38.

70. Klunk W., Engler H., Nordberg A., Wang Y., Blomqvist G., DP D.H., Bergstrom M., Savitcheva I., Huang G.-F., Estrada S., Ausen B., Debnath M., Barletta J., Price J., Sandell J., Lopresti B., Wall A., Koivisto P., Antoni G., Mathis C., Langstrom B., 2004a. Imaging Brain Amyloid in Alzheimer's Disease Using the Novel PET Tracer PIB. Annals of Neurology 55, 306319.

71. Klunk W.E., 2011. Amyloid imaging as a biomarker for cerebral beta-amyloidosis and risk prediction for Alzheimer dementia. Neurobiol Aging 32 Suppl 1, S20-36. 
72. Klunk W.E., Koeppe R.A., Price J.C., Benzinger T.L., Devous M.D., Sr., Jagust W.J., Johnson K.A., Mathis C.A., Minhas D., Pontecorvo M.J., Rowe C.C., Skovronsky D.M., Mintun M.A., 2015. The Centiloid Project: standardizing quantitative amyloid plaque estimation by PET. Alzheimers Dement 11, 1-15 e1-4. doi: 10.1016/j.jalz.2014.07.003

73. Klunk W.E., Lopresti B.J., Ikonomovic M.D., Lefterov I.M., Koldamova R.P., Abrahamson E.E., Debnath M.L., Holt D.P., Huang G.F., Shao L., DeKosky S.T., Price J.C., Mathis C.A., 2005b. Binding of the positron emission tomography tracer Pittsburgh compound-B reflects the amount of amyloid-beta in Alzheimer's disease brain but not in transgenic mouse brain. J Neurosci 25, 10598-606.

74. Klunk W.E., Price J.C., Lopresti B.J., Debnath M.L., Holt D.P., Wang Y.M., Huang G.F., Shao L., Meltzer C., DeKosky S.T., Mathis C.A., 2004b. Human amyloid-imaging studies in controls, mild cognitive impairment and Alzheimer's disease using Pittsburgh compound-B. Neurobiology Of Aging 25, S58-S58.

75. Klunk W.E., Price J.C., Mathis C.A., Tsopelas N.D., Lopresti B.J., Ziolko S.K., Bi W., Hoge J.A., Cohen A.D., Ikonomovic M.D., Saxton J.A., Snitz B.E., Pollen D.A., Moonis M., Lippa C.F., Swearer J.M., Johnson K.A., Rentz D.M., Fischman A.J., Aizenstein H.J., DeKosky S.T., 2007. Amyloid deposition begins in the striatum of presenilin-1 mutation carriers from two unrelated pedigrees. J Neurosci 27, 6174-84.

76. Koivunen J., Pirttila T., Kemppainen N., Aalto S., Herukka S.K., Jauhianen A.M., Hanninen T., Hallikainen M., Nagren K., Rinne J.O., Soininen H., 2008. PET amyloid ligand [11C]PIB uptake and cerebrospinal fluid beta-amyloid in mild cognitive impairment. Dement Geriatr Cogn Disord 26, 378-83. doi: 10.1159/000163927

77. Koivunen J., Scheinin N., Virta J., Aalto S., Vahlberg T., Någren K., Helin S., Parkkola R., Viitanen M., Rinne J., 2011. Amyloid PET imaging in patients with mild cognitive impairment $A$ 2-year follow-up study. Neurology 76, 1085-1090.

78. Kok E., Haikonen S., Luoto T., Huhtala H., Goebeler S., Haapasalo H., Karhunen P.J., 2009. Apolipoprotein E-dependent accumulation of Alzheimer disease-related lesions begins in middle age. Ann Neurol 65, 650-7. doi: 10.1002/ana.21696

79. Korecka M., Waligorska T., Figurski M., Toledo J.B., Arnold S.E., Grossman M., Trojanowski J.Q., Shaw L.M., 2014. Qualification of a surrogate matrix-based absolute quantification method for amyloid-beta(4)(2) in human cerebrospinal fluid using 2D UPLCtandem mass spectrometry. J Alzheimers Dis 41, 441-51. doi: 10.3233/JAD-132489

80. Kuhlmann J., Andreasson U., Pannee J., Bjerke M., Portelius E., Leinenbach A., Bittner T., Korecka M., Jenkins R.G., Vanderstichele H., Stoops E., Lewczuk P., Shaw L.M., Zegers I., Schimmel H., Zetterberg H., Blennow K., proteins I.W.G.o.S.o.C., 2017. CSF Abeta1-42 - an excellent but complicated Alzheimer's biomarker - a route to standardisation. Clin Chim Acta 467, 27-33. doi: 10.1016/j.cca.2016.05.014

81. Landau S.M., Breault C., Joshi A.D., Pontecorvo M., Mathis C.A., Jagust W.J., Mintun M.A., 2013a. Amyloid-beta imaging with Pittsburgh compound $B$ and florbetapir: comparing radiotracers and quantification methods. Journal of nuclear medicine : official publication, Society of Nuclear Medicine 54, 70-7. doi: 10.2967/jnumed.112.109009

82. Landau S.M., Lu M., Joshi A.D., Pontecorvo M., Mintun M.A., Trojanowski J.Q., Shaw L.M., Jagust W.J., 2013b. Comparing PET imaging and CSF measurements of Ass. Annals of Neurology. doi: 10.1002/ana.23908 
83. Landt J., D'Abrera J.C., Holland A.J., Aigbirhio F.I., Fryer T.D., Canales R., Hong Y.T., Menon D.K., Baron J.C., Zaman S.H., 2011. Using Positron Emission Tomography and Carbon 11Labeled Pittsburgh Compound B to Image Brain Fibrillar \{beta\}-Amyloid in Adults With Down Syndrome: Safety, Acceptability, and Feasibility. Archives of Neurology. doi: 10.1001/archneurol.2011.36

84. Lao P.J., Betthauser T.J., Hillmer A.T., Price J.C., Klunk W.E., Mihaila I., Higgins A.T., Bulova P.D., Hartley S.L., Hardison R., Tumuluru R.V., Murali D., Mathis C.A., Cohen A.D., Barnhart T.E., Devenny D.A., Mailick M.R., Johnson S.C., Handen B.L., Christian B.T., 2016. The effects of normal aging on amyloid-beta deposition in nondemented adults with Down syndrome as imaged by carbon 11-labeled Pittsburgh compound B. Alzheimers Dement 12, 38090. doi: 10.1016/j.jalz.2015.05.013

85. Lautner R., Palmqvist S., Mattsson N., Andreasson U., Wallin A., Palsson E., Jakobsson J., Herukka S.K., Owenius R., Olsson B., Hampel H., Rujescu D., Ewers M., Landen M., Minthon L., Blennow K., Zetterberg H., Hansson O., Alzheimer's Disease Neuroimaging I., 2014. Apolipoprotein E genotype and the diagnostic accuracy of cerebrospinal fluid biomarkers for Alzheimer disease. JAMA Psychiatry 71, 1183-91. doi: 10.1001/jamapsychiatry.2014.1060 86. Leal S.L., Lockhart S.N., Maass A., Bell R.K., Jagust W.J., 2018. Subthreshold Amyloid Predicts Tau Deposition in Aging. J Neurosci 38, 4482-4489. doi: 10.1523/JNEUROSCI.048518.2018

87. Leinenbach A., Pannee J., Dulffer T., Huber A., Bittner T., Andreasson U., Gobom J., Zetterberg H., Kobold U., Portelius E., Blennow K., proteins I.S.D.W.G.o.C., 2014. Mass spectrometry-based candidate reference measurement procedure for quantification of amyloid-beta in cerebrospinal fluid. Clin Chem 60, 987-94. doi: 10.1373/clinchem.2013.220392 88. Leinonen V., Alafuzoff I., Aalto S., Suotunen T., Savolainen S., Nagren K., Tapiola T., Pirttila T., Rinne J., Jaaskelainen J.E., Soininen H., Rinne J.O., 2008. Assessment of \{beta\}Amyloid in a Frontal Cortical Brain Biopsy Specimen and by Positron Emission Tomography With Carbon 11-Labeled Pittsburgh Compound B. 65, 1304-1309. doi:

10.1001/archneur.65.10.noc80013

89. Leuzy A., Carter S.F., Chiotis K., Almkvist O., Wall A., Nordberg A., 2015. Concordance and Diagnostic Accuracy of [11C]PIB PET and Cerebrospinal Fluid Biomarkers in a Sample of Patients with Mild Cognitive Impairment and Alzheimer's Disease. J Alzheimers Dis 45, 1077-88. doi: 10.3233/JAD-142952

90. Leuzy A., Chiotis K., Hasselbalch S.G., Rinne J.O., de Mendonca A., Otto M., Lleo A., Castelo-Branco M., Santana I., Johansson J., Anderl-Straub S., von Arnim C.A., Beer A., Blesa R., Fortea J., Herukka S.K., Portelius E., Pannee J., Zetterberg H., Blennow K., Nordberg A., 2016. Pittsburgh compound B imaging and cerebrospinal fluid amyloid-beta in a multicentre European memory clinic study. Brain 139, 2540-53. doi: 10.1093/brain/aww160

91. Lewczuk P., Matzen A., Blennow K., Parnetti L., Molinuevo J.L., Eusebi P., Kornhuber J., Morris J.C., Fagan A.M., 2017. Cerebrospinal Fluid Abeta42/40 Corresponds Better than Abeta42 to Amyloid PET in Alzheimer's Disease. J Alzheimers Dis 55, 813-822. doi: 10.3233/JAD160722

92. Lim Y.Y., Mormino E.C., Alzheimer's Disease Neuroimaging I., 2017. APOE genotype and early beta-amyloid accumulation in older adults without dementia. Neurology 89, 1028-1034. doi: 10.1212/WNL.0000000000004336 
93. Lim Y.Y., Pietrzak R.H., Bourgeat P., Ames D., Ellis K.A., Rembach A., Harrington K., Salvado O., Martins R.N., Snyder P.J., Masters C.L., Rowe C.C., Villemagne V.L., Maruff P., 2015. Relationships between performance on the Cogstate Brief Battery, neurodegeneration, and Abeta accumulation in cognitively normal older adults and adults with $\mathrm{MCl}$. Arch Clin Neuropsychol 30, 49-58. doi: 10.1093/arclin/acu068

94. Maetzler W., Liepelt I., Reimold M., ReischI G., Solbach C., Becker C., Schulte C., Leyhe T., Keller S., Melms A., Gasser T., Berg D., 2009. Cortical PIB binding in Lewy body disease is associated with Alzheimer-like characteristics. Neurobiology of Disease 34, 107-112.

95. Mahley R.W., Huang Y., 2006. Apolipoprotein (apo) E4 and Alzheimer's disease: unique conformational and biophysical properties of apoE4 can modulate neuropathology. Acta Neurol Scand Suppl 185, 8-14. doi: 10.1111/j.1600-0404.2006.00679.x

96. Mathis C.A., Kuller L.H., Klunk W.E., Snitz B.E., Price J.C., Weissfeld L.A., Rosario B.L., Lopresti B.J., Saxton J.A., Aizenstein H.J., McDade E.M., Kamboh M.I., DeKosky S.T., Lopez O.L., 2013. In vivo assessment of amyloid-beta deposition in nondemented very elderly subjects. Ann Neurol 73, 751-61. doi: 10.1002/ana.23797

97. Mattsson N., Andreasson U., Persson S., Arai H., Batish S.D., Bernardini S., BocchioChiavetto L., Blankenstein M.A., Carrillo M.C., Chalbot S., Coart E., Chiasserini D., Cutler N., Dahlfors G., Duller S., Fagan A.M., Forlenza O., Frisoni G.B., Galasko D., Galimberti D., Hampel H., Handberg A., Heneka M.T., Herskovits A.Z., Herukka S.K., Holtzman D.M., Humpel C., Hyman B.T., Iqbal K., Jucker M., Kaeser S.A., Kaiser E., Kapaki E., Kidd D., Klivenyi P., Knudsen C.S., Kummer M.P., Lui J., Llado A., Lewczuk P., Li Q.X., Martins R., Masters C., McAuliffe J., Mercken M., Moghekar A., Molinuevo J.L., Montine T.J., Nowatzke W., O'Brien R., Otto M., Paraskevas G.P., Parnetti L., Petersen R.C., Prvulovic D., de Reus H.P., Rissman R.A., Scarpini E., Stefani A., Soininen H., Schroder J., Shaw L.M., Skinningsrud A., Skrogstad B., Spreer A., Talib L., Teunissen C., Trojanowski J.Q., Tumani H., Umek R.M., Van Broeck B., Vanderstichele H., Vecsei L., Verbeek M.M., Windisch M., Zhang J., Zetterberg H., Blennow K., 2011. The Alzheimer's Association external quality control program for cerebrospinal fluid biomarkers. Alzheimers Dement 7, 386-395 e6. doi: 10.1016/j.jalz.2011.05.2243

98. Mattsson N., Groot C., Jansen W.J., Landau S.M., Villemagne V.L., Engelborghs S., Mintun M.M., Lleo A., Molinuevo J.L., Jagust W.J., Frisoni G.B., Ivanoiu A., Chetelat G., Resende de Oliveira C., Rodrigue K.M., Kornhuber J., Wallin A., Klimkowicz-Mrowiec A., Kandimalla R., Popp J., Aalten P.P., Aarsland D., Alcolea D., Almdahl I.S., Baldeiras I., van Buchem M.A., Cavedo E., Chen K., Cohen A.D., Forster S., Fortea J., Frederiksen K.S., Freund-Levi Y., Gill K.D., Gkatzima O., Grimmer T., Hampel H., Herukka S.K., Johannsen P., van Laere K., de Leon M.J., Maier W., Marcusson J., Meulenbroek O., Mollergard H.M., Morris J.C., Mroczko B., Nordlund A., Prabhakar S., Peters O., Rami L., Rodriguez-Rodriguez E., Roe C.M., Ruther E., Santana I., Schroder J., Seo S.W., Soininen H., Spiru L., Stomrud E., Struyfs H., Teunissen C.E., Verhey F.R.J., Vos S.J.B., van Waalwijk van Doorn L.J.C., Waldemar G., Wallin A.K., Wiltfang J., Vandenberghe R., Brooks D.J., Fladby T., Rowe C.C., Drzezga A., Verbeek M.M., Sarazin M., Wolk D.A., Fleisher A.S., Klunk W.E., Na D.L., Sanchez-Juan P., Lee D.Y., Nordberg A., Tsolaki M., Camus V., Rinne J.O., Fagan A.M., Zetterberg H., Blennow K., Rabinovici G.D., Hansson O., van Berckel B.N.M., van der Flier W.M., Scheltens P., Visser P.J., Ossenkoppele R., 2018. Prevalence of the apolipoprotein E epsilon4 allele in amyloid beta positive subjects across the spectrum of Alzheimer's disease. Alzheimers Dement. doi: 10.1016/j.jalz.2018.02.009 
99. Mattsson N., Insel P.S., Landau S., Jagust W., Donohue M., Shaw L.M., Trojanowski J.Q., Zetterberg H., Blennow K., Weiner M., Alzheimer's Disease Neuroimaging I., 2014. Diagnostic accuracy of CSF Ab42 and florbetapir PET for Alzheimer's disease. Ann Clin Transl Neurol 1, 53443. doi: $10.1002 / a c n 3.81$

100. Mattsson N., Zetterberg H., Hansson O., Andreasen N., Parnetti L., Jonsson M., Herukka S.K., van der Flier W.M., Blankenstein M.A., Ewers M., Rich K., Kaiser E., Verbeek M., Tsolaki M., Mulugeta E., Rosen E., Aarsland D., Visser P.J., Schroder J., Marcusson J., de Leon M., Hampel H., Scheltens P., Pirttila T., Wallin A., Jonhagen M.E., Minthon L., Winblad B., Blennow K., 2009. CSF biomarkers and incipient Alzheimer disease in patients with mild cognitive impairment. JAMA 302, 385-93. doi: 10.1001/jama.2009.1064

101. McDade E., Wang G., Gordon B.A., Hassenstab J., Benzinger T.L.S., Buckles V., Fagan A.M., Holtzman D.M., Cairns N.J., Goate A.M., Marcus D.S., Morris J.C., Paumier K., Xiong C., Allegri R., Berman S.B., Klunk W., Noble J., Ringman J., Ghetti B., Farlow M., Sperling R.A., Chhatwal J., Salloway S., Graff-Radford N.R., Schofield P.R., Masters C., Rossor M.N., Fox N.C., Levin J., Jucker M., Bateman R.J., Dominantly Inherited Alzheimer N., 2018. Longitudinal cognitive and biomarker changes in dominantly inherited Alzheimer disease. Neurology 91, e1295-e1306. doi: 10.1212/WNL.0000000000006277

102. McLean C.A., Cherny R.A., Fraser F.W., Fuller S.J., Smith M.J., Beyreuther K., Bush A.I., Masters C.L., 1999. Soluble pool of Abeta amyloid as a determinant of severity of neurodegeneration in Alzheimer's disease. Ann Neurol 46, 860-6.

103. Mintun M.A., LaRossa G.A., Sheline Y.I., Dence C.S., Lee S.Y., Mach R.H., Klunk W.E., Mathis C.A., DeKosky S.T., Morris J.C., 2006. $\left[{ }^{11}\right.$ C]PIB in a Nondemented Population: Potential Antecedent Marker of Alzheimer Disease. Neurology (in press).

104. Mirra S.S., Heyman A., McKeel D., Sumi S.M., Crain B.J., Brownlee L.M., Vogel F.S., Hughes J.P., van Belle G., Berg L., 1991. The Consortium to Establish a Registry for Alzheimer's Disease (CERAD). Part II. Standardization of the neuropathologic assessment of Alzheimer's disease. Neurology 41, 479-486.

105. Mishra S., Blazey T.M., Holtzman D.M., Cruchaga C., Su Y., Morris J.C., Benzinger T.L.S., Gordon B.A., 2018. Longitudinal brain imaging in preclinical Alzheimer disease: impact of APOE epsilon4 genotype. Brain 141, 1828-1839. doi: 10.1093/brain/awy103

106. Mormino E.C., Betensky R.A., Hedden T., Schultz A.P., Amariglio R.E., Rentz D.M., Johnson K.A., Sperling R.A., 2014a. Synergistic effect of beta-amyloid and neurodegeneration on cognitive decline in clinically normal individuals. JAMA Neurol 71, 1379-85. doi:

10.1001/jamaneurol.2014.2031

107. Mormino E.C., Betensky R.A., Hedden T., Schultz A.P., Ward A., Huijbers W., Rentz D.M., Johnson K.A., Sperling R.A., Alzheimer's Disease Neuroimaging I., Australian Imaging B., Lifestyle Flagship Study of A., Harvard Aging Brain S., 2014b. Amyloid and APOE epsilon4 interact to influence short-term decline in preclinical Alzheimer disease. Neurology 82, 1760-7. doi: 10.1212/WNL.0000000000000431

108. Mormino E.C., Brandel M.G., Madison C.M., Rabinovici G.D., Marks S., Baker S.L., Jagust W.J., 2012. Not quite PIB-positive, not quite PIB-negative: Slight PIB elevations in elderly normal control subjects are biologically relevant. Neuroimage 59, 1152-60. doi:

10.1016/j.neuroimage.2011.07.098 
109. Mormino E.C., Kluth J.T., Madison C.M., Rabinovici G.D., Baker S.L., Miller B.L., Koeppe R.A., Mathis C.A., Weiner M.W., Jagust W.J., 2009. Episodic memory loss is related to hippocampal-mediated beta-amyloid deposition in elderly subjects. Brain : a journal of neurology 132, 1310-23. doi: 10.1093/brain/awn320

110. Mormino E.C., Smiljic A., Hayenga A.O., Onami S.H., Greicius M.D., Rabinovici G.D., Janabi M., Baker S.L., Yen I.V., Madison C.M., Miller B.L., Jagust W.J., 2011. Relationships between beta-amyloid and functional connectivity in different components of the default mode network in aging. Cerebral cortex 21, 2399-407. doi: 10.1093/cercor/bhr025

111. Morris J.C., Roe C.M., Xiong C., Fagan A.M., Goate A.M., Holtzman D.M., Mintun M.A., 2010. APOE predicts amyloid-beta but not tau Alzheimer pathology in cognitively normal aging. Ann Neurol 67, 122-31.

112. Nakamura A., Kaneko N., Villemagne V.L., Kato T., Doecke J., Dore V., Fowler C., Li Q.X., Martins R., Rowe C., Tomita T., Matsuzaki K., Ishii K., Ishii K., Arahata Y., Iwamoto S., Ito K., Tanaka K., Masters C.L., Yanagisawa K., 2018. High performance plasma amyloid-beta biomarkers for Alzheimer's disease. Nature 554, 249-254. doi: 10.1038/nature25456 113. Navitsky M., Joshi A.D., Kennedy I., Klunk W.E., Rowe C.C., Wong D.F., Pontecorvo M.J., Mintun M.A., Devous M.D., Sr., 2018. Standardization of amyloid quantitation with florbetapir standardized uptake value ratios to the Centiloid scale. Alzheimers Dement. doi:

10.1016/j.jalz.2018.06.1353

114. Nebes R.D., Snitz B.E., Cohen A.D., Aizenstein H.J., Saxton J.A., Halligan E.M., Mathis C.A., Price J.C., Kamboh M.I., Weissfeld L.A., 2013. Cognitive aging in persons with minimal amyloid- $\beta$ and white matter hyperintensities. Neuropsychologia 51, 2202-2209.

115. Nelson L.D., Siddarth P., Kepe V., Scheibel K.E., Huang S.C., Barrio J.R., Small G.W., 2011. Positron Emission Tomography of Brain \{beta\}-Amyloid and Tau Levels in Adults With Down Syndrome. Archives of Neurology 68, 768-74. doi: 10.1001/archneurol.2011.104

116. Ng S., Villemagne V.L., Berlangieri S., Lee S.T., Cherk M., Gong S.J., Ackermann U., Saunder T., Tochon-Danguy H., Jones G., Smith C., O'Keefe G., Masters C.L., Rowe C.C., 2007. Visual assessment versus quantitative assessment of 11C-PIB PET and 18F-FDG PET for detection of Alzheimer's disease. J Nucl Med 48, 547-52.

117. Okello A., Koivunen J., Edison P., Archer H., Turkheimer F., Någren K.u., Bullock R., Walker Z., Kennedy A., Fox N., 2009. Conversion of amyloid positive and negative $\mathrm{MCl}$ to AD over 3 years An 11C-PIB PET study. Neurology 73, 754-760.

118. Olsson B., Lautner R., Andreasson U., Ohrfelt A., Portelius E., Bjerke M., Holtta M., Rosen C., Olsson C., Strobel G., Wu E., Dakin K., Petzold M., Blennow K., Zetterberg H., 2016. CSF and blood biomarkers for the diagnosis of Alzheimer's disease: a systematic review and metaanalysis. Lancet Neurol 15, 673-684. doi: 10.1016/S1474-4422(16)00070-3

119. Ossenkoppele R., Jansen W.J., Rabinovici G.D., Knol D.L., van der Flier W.M., van Berckel B.N., Scheltens P., Visser P.J., Amyloid P.E.T.S.G., Verfaillie S.C., Zwan M.D., Adriaanse S.M., Lammertsma A.A., Barkhof F., Jagust W.J., Miller B.L., Rosen H.J., Landau S.M., Villemagne V.L., Rowe C.C., Lee D.Y., Na D.L., Seo S.W., Sarazin M., Roe C.M., Sabri O., Barthel H., Koglin N., Hodges J., Leyton C.E., Vandenberghe R., van Laere K., Drzezga A., Forster S., Grimmer T., Sanchez-Juan P., Carril J.M., Mok V., Camus V., Klunk W.E., Cohen A.D., Meyer P.T., Hellwig S., Newberg A., Frederiksen K.S., Fleisher A.S., Mintun M.A., Wolk D.A., Nordberg A., Rinne J.O., Chetelat G., Lleo A., Blesa R., Fortea J., Madsen K., Rodrigue K.M., Brooks D.J., 2015. Prevalence 
of amyloid PET positivity in dementia syndromes: a meta-analysis. JAMA 313, 1939-49. doi: 10.1001/jama.2015.4669

120. Ovod V., Ramsey K.N., Mawuenyega K.G., Bollinger J.G., Hicks T., Schneider T., Sullivan M., Paumier K., Holtzman D.M., Morris J.C., Benzinger T., Fagan A.M., Patterson B.W., Bateman R.J., 2017. Amyloid beta concentrations and stable isotope labeling kinetics of human plasma specific to central nervous system amyloidosis. Alzheimers Dement 13, 841-849. doi: 10.1016/j.jalz.2017.06.2266

121. Palmqvist S., Mattsson N., Hansson O., Alzheimer's Disease Neuroimaging I., 2016. Cerebrospinal fluid analysis detects cerebral amyloid-beta accumulation earlier than positron emission tomography. Brain 139, 1226-36. doi: 10.1093/brain/aww015

122. Palmqvist S., Zetterberg H., Blennow K., Vestberg S., Andreasson U., Brooks D.J., Owenius R., Hagerstrom D., Wollmer P., Minthon L., Hansson O., 2014. Accuracy of brain amyloid detection in clinical practice using cerebrospinal fluid beta-amyloid 42: a crossvalidation study against amyloid positron emission tomography. JAMA Neurol 71, 1282-9. doi: 10.1001/jamaneurol.2014.1358

123. Pannee J., Portelius E., Minthon L., Gobom J., Andreasson U., Zetterberg H., Hansson O., Blennow K., 2016. Reference measurement procedure for CSF amyloid beta (Abeta)1-42 and the CSF Abeta1-42 /Abeta1-40 ratio - a cross-validation study against amyloid PET. J Neurochem 139, 651-658. doi: 10.1111/jnc.13838

124. Papp K.V., Mormino E.C., Amariglio R.E., Munro C., Dagley A., Schultz A.P., Johnson K.A., Sperling R.A., Rentz D.M., 2016. Biomarker validation of a decline in semantic processing in preclinical Alzheimer's disease. Neuropsychology 30, 624.

125. Petersen R.C., Wiste H.J., Weigand S.D., Rocca W.A., Roberts R.O., Mielke M.M., Lowe V.J., Knopman D.S., Pankratz V.S., Machulda M.M., 2016. Association of elevated amyloid levels with cognition and biomarkers in cognitively normal people from the community. JAMA neurology 73, 85-92.

126. Pike K.E., Ellis K.A., Villemagne V.L., Good N., Chételat G., Ames D., Szoeke C., Laws S.M., Verdile G., Martins R.N., 2011. Cognition and beta-amyloid in preclinical Alzheimer's disease: data from the AIBL study. Neuropsychologia 49, 2384-2390.

127. Pike K.E., G. S., Villemagne V.L., Ng S., Moss S.A., Maruff P., Mathis C.A., Klunk W.E., Masters C.L., Rowe C.C., 2007. $\beta$-Amyloid imaging and memory in nondemented individuals: Evidence for preclinical Alzheimer's disease. Brain (in press).

128. Portelius E., Hansson S.F., Tran A.J., Zetterberg H., Grognet P., Vanmechelen E., Hoglund K., Brinkmalm G., Westman-Brinkmalm A., Nordhoff E., Blennow K., Gobom J., 2008. Characterization of tau in cerebrospinal fluid using mass spectrometry. J Proteome Res 7, 211420. doi: $10.1021 /$ pr7008669

129. Price J.C., Klunk W.E., Lopresti B.J., Lu X., Hoge J.A., Ziolko S.K., Holt D.P., Meltzer C.C., DeKosky S.T., Mathis C.A., 2005 Kinetic modeling of amyloid binding in humans using PET imaging and Pittsburgh Compound-B. J Cereb Blood Flow Metab 25, 1528-1547.

130. Rabinovici G.D., Furst A.J., Alkalay A., Racine C.A., O'Neil J.P., Janabi M., Baker S.L., Agarwal N., Bonasera S.J., Mormino E.C., Weiner M.W., Gorno-Tempini M.L., Rosen H.J., Miller B.L., Jagust W.J., 2010. Increased metabolic vulnerability in early-onset Alzheimer's disease is not related to amyloid burden. Brain : a journal of neurology $133,512-28$. doi:

10.1093/brain/awp326 
131. Rabinovici G.D., Furst A.J., O'Neil J.P., Racine C.A., Mormino E.C., Baker S.L., Chetty S., Patel P., Pagliaro T.A., Klunk W.E., Mathis C.A., Rosen H.J., Miller B.L., Jagust W.J., 2007. 11C-PIB PET imaging in Alzheimer disease and frontotemporal lobar degeneration. Neurology 68, 120512.

132. Reiman E.M., Chen K., Liu X., Bandy D., Yu M., Lee W., Ayutyanont N., Keppler J., Reeder S.A., Langbaum J.B.S., Alexander G.E., Klunk W.E., Mathis C.A., Price J.C., Aizenstein H.J., DeKosky S.T., Caselli R.J. (2009) Fibrillar amyloid- $\left.\right|^{2}$ burden in cognitively normal people at 3 levels of genetic risk for Alzheimer's disease. pp. 6820-6825

133. Remes A.M., Laru L., Tuominen H., Aalto S., Kemppainen N., Mononen H., Nagren K., Parkkola R., Rinne J.O., 2008. Carbon 11-labeled pittsburgh compound B positron emission tomographic amyloid imaging in patients with APP locus duplication. Arch Neurol 65, 540-4. doi: 10.1001/archneur.65.4.540

134. Rentz D.M., Amariglio R.E., Becker J.A., Frey M., Olson L.E., Frishe K., Carmasin J., Maye J.E., Johnson K.A., Sperling R.A., 2011. Face-name associative memory performance is related to amyloid burden in normal elderly. Neuropsychologia 49, 2776-83.

135. Resnick S.M., Sojkova J., Zhou Y., An Y., Ye W., Holt D.P., Dannals R.F., Mathis C.A., Klunk W.E., Ferrucci L., Kraut M.A., Wong D.F., 2010. Longitudinal cognitive decline is associated with fibrillar amyloid-beta measured by [11C]PiB. Neurology 74, 807-15.

136. Roberts R.O., Aakre J.A., Kremers W.K., Vassilaki M., Knopman D.S., Mielke M.M., Alhurani R., Geda Y.E., Machulda M.M., Coloma P., 2018. Prevalence and Outcomes of Amyloid Positivity Among Persons Without Dementia in a Longitudinal, Population-Based Setting. JAMA neurology.

137. Roe C.M., Mintun M.A., D'Angelo G., Xiong C., Grant E.A., Morris J.C., 2008. Alzheimer disease and cognitive reserve: variation of education effect with carbon 11-labeled Pittsburgh Compound B uptake. Arch Neurol 65, 1467-71.

138. Rosen R.F., Ciliax B.J., Wingo T.S., Gearing M., Dooyema J., Lah J.J., Ghiso J.A., LeVine H., 3rd, Walker L.C., 2010. Deficient high-affinity binding of Pittsburgh compound B in a case of Alzheimer's disease. Acta Neuropathol 119, 221-33.

139. Rowe C.C., Bourgeat P., Ellis K.A., Brown B., Lim Y.Y., Mulligan R., Jones G., Maruff P., Woodward M., Price R., Robins P., Tochon-Danguy H., O'Keefe G., Pike K.E., Yates P., Szoeke C., Salvado O., Macaulay S.L., O'Meara T., Head R., Cobiac L., Savage G., Martins R., Masters C.L., Ames D., Villemagne V.L., 2013. Predicting Alzheimer disease with beta-amyloid imaging: Results from the Australian imaging, biomarkers, and lifestyle study of ageing. Annals of Neurology 74, 905-13. doi: 10.1002/ana.24040

140. Rowe C.C., Dore V., Jones G., Baxendale D., Mulligan R.S., Bullich S., Stephens A.W., De Santi S., Masters C.L., Dinkelborg L., Villemagne V.L., 2017. (18)F-Florbetaben PET beta-amyloid binding expressed in Centiloids. Eur J Nucl Med Mol Imaging 44, 2053-2059. doi:

10.1007/s00259-017-3749-6

141. Rowe C.C., Ellis K.A., Rimajova M., Bourgeat P., Pike K.E., Jones G., Fripp J., TochonDanguy H., Morandeau L., O'Keefe G., Price R., Raniga P., Robins P., Acosta O., Lenzo N., Szoeke C., Salvado O., Head R., Martins R., Masters C.L., Ames D., Villemagne V.L., 2010. Amyloid imaging results from the Australian Imaging, Biomarkers and Lifestyle (AIBL) study of aging. Neurobiol Aging 31, 1275-83. 
142. Rowe C.C., Jones G., Dore V., Pejoska S., Margison L., Mulligan R.S., Chan J.G., Young K., Villemagne V.L., 2016. Standardized Expression of 18F-NAV4694 and 11C-PiB beta-Amyloid PET Results with the Centiloid Scale. J Nucl Med 57, 1233-7. doi: 10.2967/jnumed.115.171595

143. Rowe C.C., Ng S., Ackermann U., Gong S.J., Pike K., Savage G., Cowie T.F., Dickinson K.L., Maruff P., Darby D., Smith C., Woodward M., Merory J., Tochon-Danguy H., O'Keefe G., Klunk W.E., Mathis C.A., Price J.C., Masters C.L., Villemagne V.L., 2007. Imaging beta-amyloid burden in aging and dementia. Neurology 68, 1718-25.

144. Sabri O., Sabbagh M.N., Seibyl J., Barthel H., Akatsu H., Ouchi Y., Senda K., Murayama S., Ishii K., Takao M., Beach T.G., Rowe C.C., Leverenz J.B., Ghetti B., Ironside J.W., Catafau A.M., Stephens A.W., Mueller A., Koglin N., Hoffmann A., Roth K., Reininger C., Schulz-Schaeffer W.J., Florbetaben Phase 3 Study G., 2015. Florbetaben PET imaging to detect amyloid beta plaques in Alzheimer's disease: phase 3 study. Alzheimers Dement 11, 964-74. doi:

10.1016/j.jalz.2015.02.004

145. Scheltens P., Blennow K., Breteler M.M., de Strooper B., Frisoni G.B., Salloway S., Van der Flier W.M., 2016. Alzheimer's disease. Lancet 388, 505-17. doi: 10.1016/S01406736(15)01124-1

146. Schindler S.E., Gray J.D., Gordon B.A., Xiong C., Batrla-Utermann R., Quan M., Wahl S., Benzinger T.L.S., Holtzman D.M., Morris J.C., Fagan A.M., 2018. Cerebrospinal fluid biomarkers measured by Elecsys assays compared to amyloid imaging. Alzheimers Dement. doi:

10.1016/j.jalz.2018.01.013

147. Scholl M., Wall A., Thordardottir S., Ferreira D., Bogdanovic N., Langstrom B., Almkvist O., Graff C., Nordberg A., 2012. Low PiB PET retention in presence of pathologic CSF biomarkers in Arctic APP mutation carriers. Neurology 79, 229-36. doi: 10.1212/WNL.0b013e31825fdf18 148. Shaw L.M., Vanderstichele H., Knapik-Czajka M., Clark C.M., Aisen P.S., Petersen R.C., Blennow K., Soares H., Simon A., Lewczuk P., Dean R., Siemers E., Potter W., Lee V.M., Trojanowski J.Q., Alzheimer's Disease Neuroimaging I., 2009. Cerebrospinal fluid biomarker signature in Alzheimer's disease neuroimaging initiative subjects. Ann Neurol 65, 403-13. doi: 10.1002/ana.21610

149. Sjogren M., Vanderstichele H., Agren H., Zachrisson O., Edsbagge M., Wikkelso C., Skoog I., Wallin A., Wahlund L.O., Marcusson J., Nagga K., Andreasen N., Davidsson P., Vanmechelen E., Blennow K., 2001. Tau and Abeta42 in cerebrospinal fluid from healthy adults 21-93 years of age: establishment of reference values. Clin Chem 47, 1776-81.

150. Sojkova J., Driscoll I., lacono D., Zhou Y., Codispoti K.E., Kraut M.A., Ferrucci L., Pletnikova O., Mathis C.A., Klunk W.E., O'Brien R.J., Wong D.F., Troncoso J.C., Resnick S.M., 2011. In vivo fibrillar beta-amyloid detected using [11C]PiB positron emission tomography and neuropathologic assessment in older adults. Archives of Neurology 68, 232-40. doi: 10.1001/archneurol.2010.357

151. Sperling R.A., Aisen P.S., Beckett L.A., Bennett D.A., Craft S., Fagan A.M., Iwatsubo T., Jack C.R., Jr., Kaye J., Montine T.J., Park D.C., Reiman E.M., Rowe C.C., Siemers E., Stern Y., Yaffe K., Carrillo M.C., Thies B., Morrison-Bogorad M., Wagster M.V., Phelps C.H., 2011. Toward defining the preclinical stages of Alzheimer's disease: Recommendations from the National Institute on Aging-Alzheimer's Association workgroups on diagnostic guidelines for Alzheimer's disease. Alzheimers Dement 7, 280-92. 
152. Sperling R.A., LaViolette P.S., O'Keefe K., O'Brien J., Rentz D.M., Pihlajamaki M., Marshall G., Hyman B.T., Selkoe D.J., Hedden T., Buckner R.L., Becker J.A., Johnson K.A., 2009. Amyloid Deposition Is Associated with Impaired Default Network Function in Older Persons without Dementia. Neuron 63, 178-188.

153. Storandt M., Mintun M.A., Head D., Morris J.C., 2009. Cognitive decline and brain volume loss as signatures of cerebral amyloid-beta peptide deposition identified with Pittsburgh compound B: cognitive decline associated with Abeta deposition. Archives of Neurology 66, 1476-81. doi: 10.1001/archneurol.2009.272

154. Strozyk D., Blennow K., White L.R., Launer L.J., 2003. CSF Abeta 42 levels correlate with amyloid-neuropathology in a population-based autopsy study. Neurology 60, 652-6.

155. Styren S.D., Hamilton R.L., Styren G.C., Klunk W.E., 2000. X-34, a fluorescent derivative of Congo red: A novel histochemical stain for Alzheimer's disease pathology. Journal of Histochemistry \& Cytochemistry 48, 1223-1232.

156. Su Y., Flores S., Hornbeck R.C., Speidel B., Vlassenko A.G., Gordon B.A., Koeppe R.A., Klunk W.E., Xiong C., Morris J.C., Benzinger T.L.S., 2018. Utilizing the Centiloid scale in crosssectional and longitudinal PiB PET studies. Neuroimage Clin 19, 406-416. doi:

10.1016/j.nicl.2018.04.022

157. Suotunen T., Hirvonen J., Immonen-Raiha P., Aalto S., Lisinen I., Arponen E., Teras M., Koski K., Sulkava R., Seppanen M., Rinne J.O., 2010. Visual assessment of [(11)C]PIB PET in patients with cognitive impairment. Eur J Nucl Med Mol Imaging 37, 1141-7.

158. Thal D.R., Rub U., Orantes M., Braak H., 2002. Phases of Ab-deposition in the human brain and its relevance for the development of AD. Neurology 58, 1791-1800.

159. Toledo J.B., Bjerke M., Chen K., Rozycki M., Jack C.R., Jr., Weiner M.W., Arnold S.E., Reiman E.M., Davatzikos C., Shaw L.M., Trojanowski J.Q., Alzheimer's Disease Neuroimaging I., 2015. Memory, executive, and multidomain subtle cognitive impairment: clinical and biomarker findings. Neurology 85, 144-53. doi: 10.1212/WNL.0000000000001738

160. Toyama H., Ye D., Ichise M., Liow J.S., Cai L., Jacobowitz D., Musachio J.L., Hong J., Crescenzo M., Tipre D., Lu J.Q., Zoghbi S., Vines D.C., Seidel J., Katada K., Green M.V., Pike V.W., Cohen R.M., Innis R.B., 2005. PET imaging of brain with the beta-amyloid probe, [(11)C]6-OHBTA-1, in a transgenic mouse model of Alzheimer's disease. Eur J Nucl Med Mol Imaging 32, 593-600.

161. Tudorascu D.L., Minhas D.S., Lao P.J., Betthauser T.J., Yu Z., Laymon C.M., Lopresti B.J., Mathis C.A., Klunk W.E., Handen B.L., Christian B.T., Cohen A.D., 2018. The use of Centiloids for applying [(11)C]PiB classification cutoffs across region-of-interest delineation methods.

Alzheimers Dement (Amst) 10, 332-339. doi: 10.1016/j.dadm.2018.03.006

162. Vandenberghe R., Van Laere K., Ivanoiu A., Salmon E., Bastin C., Triau E., Hasselbalch S., Law I., Andersen A., Korner A., 2010. 18F-flutemetamol amyloid imaging in Alzheimer disease and mild cognitive impairment: A phase 2 trial. Annals of neurology 68, 319-329.

163. Vemuri P., Lesnick T.G., Przybelski S.A., Knopman D.S., Preboske G.M., Kantarci K., Raman M.R., Machulda M.M., Mielke M.M., Lowe V.J., 2015. Vascular and amyloid pathologies are independent predictors of cognitive decline in normal elderly. Brain 138, 761-771.

164. Villain N., Chetelat G., Grassiot B., Bourgeat P., Jones G., Ellis K.A., Ames D., Martins R.N., Eustache F., Salvado O., Masters C.L., Rowe C.C., Villemagne V.L., 2012. Regional dynamics of amyloid-beta deposition in healthy elderly, mild cognitive impairment and Alzheimer's 
disease: a voxelwise PiB-PET longitudinal study. Brain 135, 2126-2139. doi:

10.1093/brain/aws125

165. Villemagne V.L., Ataka S., Mizuno T., Brooks W.S., Wada Y., Kondo M., Jones G., Watanabe Y., Mulligan R., Nakagawa M., Miki T., Shimada H., O'Keefe G.J., Masters C.L., Mori H., Rowe C.C., 2009a. High striatal amyloid beta-peptide deposition across different autosomal Alzheimer disease mutation types. Archives of Neurology 66, 1537-44. doi:

10.1001/archneurol.2009.285

166. Villemagne V.L., McLean C.A., Reardon K., Boyd A., Lewis V., Klug G., Jones G., Baxendale D., Masters C.L., Rowe C.C., Collins S.J. (2009b) 11C-PiB PET studies in typical sporadic Creutzfeldt-Jakob disease. pp. jnnp.2008.171496

167. Villemagne V.L., Pike K.E., Chetelat G., Ellis K.A., Mulligan R.S., Bourgeat P., Ackermann U., Jones G., Szoeke C., Salvado O., Martins R., O'Keefe G., Mathis C.A., Klunk W.E., Ames D., Masters C.L., Rowe C.C., 2011. Longitudinal assessment of Abeta and cognition in aging and Alzheimer disease. Ann Neurol 69, 181-92. doi: 10.1002/ana.22248

168. Villeneuve S., Rabinovici G.D., Cohn-Sheehy B.I., Madison C., Ayakta N., Ghosh P.M., La Joie R., Arthur-Bentil S.K., Vogel J.W., Marks S.M., Lehmann M., Rosen H.J., Reed B., Olichney J., Boxer A.L., Miller B.L., Borys E., Jin L.W., Huang E.J., Grinberg L.T., DeCarli C., Seeley W.W., Jagust W., 2015. Existing Pittsburgh Compound-B positron emission tomography thresholds are too high: statistical and pathological evaluation. Brain 138, 2020-33. doi: 10.1093/brain/awv112 169. Visser P.J., Verhey F., Knol D.L., Scheltens P., Wahlund L.O., Freund-Levi Y., Tsolaki M., Minthon L., Wallin A.K., Hampel H., Burger K., Pirttila T., Soininen H., Rikkert M.O., Verbeek M.M., Spiru L., Blennow K., 2009. Prevalence and prognostic value of CSF markers of Alzheimer's disease pathology in patients with subjective cognitive impairment or mild cognitive impairment in the DESCRIPA study: a prospective cohort study. Lancet Neurol 8, 61927. doi: 10.1016/S1474-4422(09)70139-5

170. Vlassenko A.G., Mintun M.A., Xiong C., Sheline Y.I., Goate A.M., Benzinger T.L., Morris J.C., 2011. Amyloid-beta plaque growth in cognitively normal adults: Iongitudinal [11C]Pittsburgh compound B data. Ann Neurol 70, 857-61. doi: 10.1002/ana.22608

171. Vogel J.W., Doležalová M.V., La Joie R., Marks S.M., Schwimmer H.D., Landau S.M., Jagust W.J., 2017. Subjective cognitive decline and $\beta$-amyloid burden predict cognitive change in healthy elderly. Neurology, 10.1212/WNL. 0000000000004627.

172. Vos S.J., Xiong C., Visser P.J., Jasielec M.S., Hassenstab J., Grant E.A., Cairns N.J., Morris J.C., Holtzman D.M., Fagan A.M., 2013. Preclinical Alzheimer's disease and its outcome: a longitudinal cohort study. The Lancet Neurology 12, 957-965.

173. Wegiel J., Wisniewski H.M., Morys J., Tarnawski M., Kuchna I., Dziewiatkowski J., Pirttila T., Krivimaki T., Lehtimaki T., Lach B., 1999. Neuronal loss and beta-amyloid removal in the amygdala of people with Down syndrome. Neurobiology of Aging. 20, 259-269.

174. Weiner M.W., Veitch D.P., Aisen P.S., Beckett L.A., Cairns N.J., Green R.C., Harvey D., Jack C.R., Jr., Jagust W., Morris J.C., Petersen R.C., Salazar J., Saykin A.J., Shaw L.M., Toga A.W., Trojanowski J.Q., Alzheimer's Disease Neuroimaging I., 2017. The Alzheimer's Disease Neuroimaging Initiative 3: Continued innovation for clinical trial improvement. Alzheimers Dement 13, 561-571. doi: 10.1016/j.jalz.2016.10.006

175. Whittington A., Sharp D.J., Gunn R.N., Alzheimer's Disease Neuroimaging I., 2018. Spatiotemporal Distribution of beta-Amyloid in Alzheimer Disease Is the Result of 
Heterogeneous Regional Carrying Capacities. J Nucl Med 59, 822-827. doi: 10.2967/jnumed.117.194720

176. Wiltfang J., Esselmann H., Bibl M., Hull M., Hampel H., Kessler H., Frolich L., Schroder J., Peters O., Jessen F., Luckhaus C., Perneczky R., Jahn H., Fiszer M., Maler J.M., Zimmermann R., Bruckmoser R., Kornhuber J., Lewczuk P., 2007. Amyloid beta peptide ratio $42 / 40$ but not A beta 42 correlates with phospho-Tau in patients with low- and high-CSF A beta 40 load. J Neurochem 101, 1053-9. doi: 10.1111/j.1471-4159.2006.04404.x

177. Wolk D.A., Price J.C., Saxton J.A., Snitz B.E., James J.A., Lopez O.L., Aizenstein H.J., Cohen A.D., Weissfeld L.A., Mathis C.A., Klunk W.E., De-Kosky S.T., 2009. Amyloid imaging in mild cognitive impairment subtypes. Annals of Neurology 65, 557-68. doi: 10.1002/ana.21598 178. Yau W.W., Tudorascu D.L., McDade E.M., Ikonomovic S., James J.A., Minhas D., Mowrey W., Sheu L.K., Snitz B.E., Weissfeld L., Gianaros P.J., Aizenstein H.J., Price J.C., Mathis C.A., Lopez O.L., Klunk W.E., 2015. Longitudinal assessment of neuroimaging and clinical markers in autosomal dominant Alzheimer's disease: a prospective cohort study. Lancet Neurol 14, 804813. doi: $10.1016 / \mathrm{S} 1474-4422(15) 00135-0$

179. Ye B.S., Kim H.J., Kim Y.J., Jung N.Y., Lee J.S., Lee J., Jang Y.K., Yang J.J., Lee J.M., Vogel J.W., Na D.L., Seo S.W., 2018. Longitudinal outcomes of amyloid positive versus negative amnestic mild cognitive impairments: a three-year longitudinal study. Sci Rep 8, 5557. doi: 10.1038/s41598-018-23676-w

180. Youn Y.C., Jang J.W., Han S.H., Kim H., Seok J.W., Byun J.S., Park K.Y., An S.S.A., Chun I.K., Kim S., 2017. (11)C-PIB PET imaging reveals that amyloid deposition in cases with early-onset Alzheimer's disease in the absence of known mutations retains higher levels of PIB in the basal ganglia. Clin Interv Aging 12, 1041-1048. doi: 10.2147/CIA.S132884

181. Yun H.J., Moon S.H., Kim H.J., Lockhart S.N., Choe Y.S., Lee K.H., Na D.L., Lee J.M., Seo S.W., 2017. Centiloid method evaluation for amyloid PET of subcortical vascular dementia. Sci Rep 7, 16322. doi: 10.1038/s41598-017-16236-1

182. Zetterberg H., Pedersen M., Lind K., Svensson M., Rolstad S., Eckerstrom C., Syversen S., Mattsson U.B., Ysander C., Mattsson N., Nordlund A., Vanderstichele H., Vanmechelen E., Jonsson M., Edman A., Blennow K., Wallin A., 2007. Intra-individual stability of CSF biomarkers for Alzheimer's disease over two years. J Alzheimers Dis 12, 255-60.

183. Zhang D., Shen D., 2012. Predicting future clinical changes of $\mathrm{MCl}$ patients using longitudinal and multimodal biomarkers. PloS one 7, e33182. doi:

10.1371/journal.pone.0033182

184. Zhao Y., Tudorascu D.L., Lopez O.L., Cohen A.D., Mathis C.A., Aizenstein H.J., Price J.C., Kuller L.H., Kamboh M.I., DeKosky S.T., 2018. Amyloid $\beta$ deposition and suspected nonAlzheimer pathophysiology and cognitive decline patterns for 12 years in oldest old participants without dementia. JAMA neurology 75, 88-96.

185. Zwan M., van Harten A., Ossenkoppele R., Bouwman F., Teunissen C., Adriaanse S., Lammertsma A., Scheltens P., van Berckel B., van der Flier W., 2014. Concordance between cerebrospinal fluid biomarkers and [11C]PIB PET in a memory clinic cohort. J Alzheimers Dis 41, 801-7. doi: 10.3233/JAD-132561

186. Zwan M.D., Rinne J.O., Hasselbalch S.G., Nordberg A., Lleo A., Herukka S.K., Soininen H., Law I., Bahl J.M., Carter S.F., Fortea J., Blesa R., Teunissen C.E., Bouwman F.H., van Berckel B.N., 
Visser P.J., 2016. Use of amyloid-PET to determine cutpoints for CSF markers: A multicenter study. Neurology 86, 50-8. doi: 10.1212/WNL.0000000000002081 